\title{
Léxico rural del treviño de Córdoba, Granada y Málaga
}

\section{INTRODUCCIÓN}

El interés del presente trabajo, a nuestro entender, no se halla en el valor intrínseco de los términos rurales que presentamos (cuya mayor o menor difusión en las hablas andaluzas puede ser de sobra conocida), sino en el siguiente hecho: el estudio de estas formas léxicas nos ha servido para poner de manifiesto, una vez más, el entrecruzamiento de isuglosas que singulariza el habla rural del treviño formado por las provincias de Córdoba, Granada y Málaga 2. Los especiales caracteres que reviste el polimorfismo léxico de esta zona geográfica fronteriza - más acusado si cabe que en el resto de Andalucía-, lo convierten en uno de los rasgos más peculiares, como puede imaginarse, de todos los que mostraremos adelante ${ }^{3}$. Pero más aún, $1^{\circ}$ ) hemos comprobado la inestabilidad del trazado de estas isoglosas diatópicas en la microárea del treviño, y $2 .^{\circ}$ ) nos vemos obligados a poner en entredicho, de antemano, la validez y el alcance lingüísticodialectal de estos datos, sin

1 Este trabajo continúa el "Vocabulario" de nuestro libro El habla rural del treviño de Iznájar, Villanueva de Tapia y Venta de Santa Bárbara (Granada: Ilmo. Ayuntamiento de Iznájar (Córdoba), Ediciones TAT, 1988) (99-125 y 149-227).

2 Ver mapa 0, Zona de la investigación. Sobre las dos Andalucías lingüísticas y, especialmente, sobre el cruce de las isoglosas andaluzas en un espacio tan reducido, en las cercanías del treviño, ver MONDÉJAR, Verbo, mapas 1 y 2 y su comentario cartográfico, 138-139; también MONDÉJAR, Hablas andaluzas, 305-306. Para conocer las subáreas con personalidad propia, que se han establecido dentro de nuestra extensa región, ver Alvar, Estructura, 6-10; FernánDeZ-Sevilla, Léxico, 445-449, 472-473 (mapas 1 y 2), Llorente, Coincidencias, 354-375; y NARbona, Hablas, 23 29.

3 Mondéjar, Verbo, 30: «El polimorfismo léxico [...] estaría representado [...] por el vario y heterogéneo caudal de designaciones con que se apunta a una misma realidad, pero en el mismo punto». Véase también MONDÉJAR, Bibliografía, 53-63, para los estudios sobre el léxico de las hablas andaluzas. 
el enfoque complementario de carácter sociolingüístico para el cabal entendimiento del polimorfismo desde la vertiente diastrática ${ }^{4}$.

El haz de isoglosas fonéticas, morfológicas y léxicas (que ahora nos ocupan), que convergen en este reducido ámbito geográfico de las Sierras Subbéticas, comarca natural del ángulo suroriental cordobés, tiene, a nuestro juicio, unos complejos condicionamientos de carácter físico, cultural e histórico. Muchas de las isoglosas andaluzas, cuyo trazado en el área del treviño (enclavado en el mismo centro de Andalucía) puede describirse con rigurosa minuciosidad, coinciden, no de forma casual, con otro tipo de límites actuales e históricos de manifiesta importancia; así ocurre con la Sierra de Campo Agro (Campo de Abor en la documentación histórica), en las últimas estribaciones subbéticas, que deslindaba los concejos de Loja e Iznájar y, actualmente, separa sus respectivos términos municipales, así como las provincias de Córdoba y Granada s.

Pese al acendrado arcaísmo que distingue la terminología léxica de las ocupaciones y de la vida rural en las localidades del treviño, por su aislamiento y precariedad respecto de los centros urbanos, es preciso señalar el empobrecimiento lingüisticodialectal que origina el desarrollo cultural de la comarca y la consiguiente estandarización lingüística, que está incidiendo en el polimorfismo léxico del habla ${ }^{6}$. El material que ofrecemos (recogido mediante encuestas) procede de informadores rurales de ambos sexos y hemos procurado atender a los principales factores (edad, oficio, formación escolar, etc.) que determinan la inestabilidad sociolingüística del habla del treviño, al menos en la parcela de la

4 Ver el artículo de MCMEnAmin, Geografía, 276-296, que confirma con procedimientos gráficos automáticos, respecto del seseo, ceceo y distinción, en el plano fonético-fonológico, el desplazamiento actual de las isoglosas en el Sur de Córdoba y el Norte de Málaga, aunque sin proponer una explicación; ver también GALEOTE, Habla, 35-70.

5 Para el establecimiento de áreas léxicas en zonas fronterizas donde confluye una gran diversidad de términos, ver Rafel, Area léxicas, 231-275, esp. 237-251. Este investigador anota desde una única forma léxica para toda la zona (237-240) hasta dos, tres, cuatro áreas e, incluso, la promiscuidad parcial o total.

6 Borrego, Sociolingüistica, 227 y ss., que ha puesto de manifiesto la ebullición e inestabilidad del habla de Villadepera de Sayago y ha estudiado el léxico no estándar $(43,8 \%)$, con una mayor sinonimia que el «vocabulario oficial» por ser importado; se afirma en la convicción de que la imagen real de un habla no puede limitarse a los rasgos diferenciales, sino que, además, es importante la penetración del vocabulario estándar, los factores socioculturales, las actitudes sociolingüísticas de los hablantes, etc. 
onomasiología agraria ?. De especial relevancia lingüística y sociocultural es el hecho de que hombres con veinticinco o treinta años ignoren gran parte de las denominaciones rurales, que contienden con las formas innovadoras del léxico estándar, de la lengua general.

Las siguientes notas de carácter socioeconómico, básicamente, pueden ayudarnos a comprender los hechos sociolingüísticos apuntados.

El predominio del olivar en la agricultura de nuestra comarca (incluidas las restantes localidades de las Subbéticas) ${ }^{8}$, que ocasiona problemas técnicos, humanos y económicos, unido a la crisis de la estructura agraria, origina una fuerte crisis coyuntural y el deterioro del sistema tradicional de la explotación olivarera ${ }^{9}$. Este monocultivo provoca el paro laboral durante largas temporadas, excepto en la época de la recolección, cuando escasea la mano de obra. En consecuencia, las familias de los pequeños propietarios autosuficientes del treviño, muy abundantes, necesitan incrementar las rentas de las hectáreas de olivar con los ingresos de los hijos mayores solteros que emigran eventualmente a la vendimia francesa, a la hostelería de las áreas turísticas, etc. Otros jóvenes de este escalón social campesino, en cambio, emigran y desertan de la labor para hacerse «futuros miembros de la clase media baja urbana», trabajando en la construcción, como conductores, mecánicos, etc. ${ }^{10}$.

La mecanización, por su parte, cada vez más generalizada en el área del treviño, debido a los notables avances tecnológicos que se han introducido en las últimas décadas en el campo andaluz (tractores, máquinas segadoras, trilladoras y cosechadoras) está haciendo caer en el olvido las faenas tradicionales ${ }^{11}$ : las sementeras y el ariego con la yunta; la siega, la barcina, la trilla y el aviento, a título de ejemplo. Los modernos herbicidas han sustituido el amocafre, la charría o el escardillo para escardar, por la "máquina de echar líquido". Desaparecen las malas hierbas y se olvidan sus nombres populares. Únicamente, determinadas parcelas del léxico rural se oponen a ser relegadas en el olvido.

7 Ibidem, 37: «[la situación sociolingüística de una comunidad] no puede verse nunca como un estado consolidado, sino como un haz de tendencias en distinto grado de expansión, que proceden del pasado y apuntan hacia el futuro». Cf. Guillén, Habla culta, 23-40 para el estudio de la frecuencia del léxico común en función de variables sociolingüísticas, en el estrato culto del habla urbana de Sevilla; y 78-150 para el contraste sociolingüístico del léxico común.

8 Ver ORTEGA, El Sur, II, 38, cuadro 50: actualmente en Iznájar, el olivar ocupa el $55,1 \%$ de la superficie cultivable, los cerales ocupan el $25 \%$ y el regadío el $1 \%$.

9 Ibidem, II, 157-1666.

10 Ibidem, II, 119-120.

11 Ibidem, II, 191-193 sobre el grado de mecanización del olivar. 
Algunos muchachos - cuyos padres labran la tierra-, de edades comprendidas entre los 20 y 25 años, pese a haber vivido en estrecho contacto con la vida rural, aunque ahora se han distanciado porque cursan estudios universitarios, nos han demostrado en encuesta directa que desconocen aproximadamente el $80 \%$ de los términos que aquí se relacionan y estudian; o, con un poco más de suerte, que conocen y han oído esporádicamente una cuarta parte de los mismos pero no sabrían a qué se refieren algunos ni en qué situaciones usarlos. 


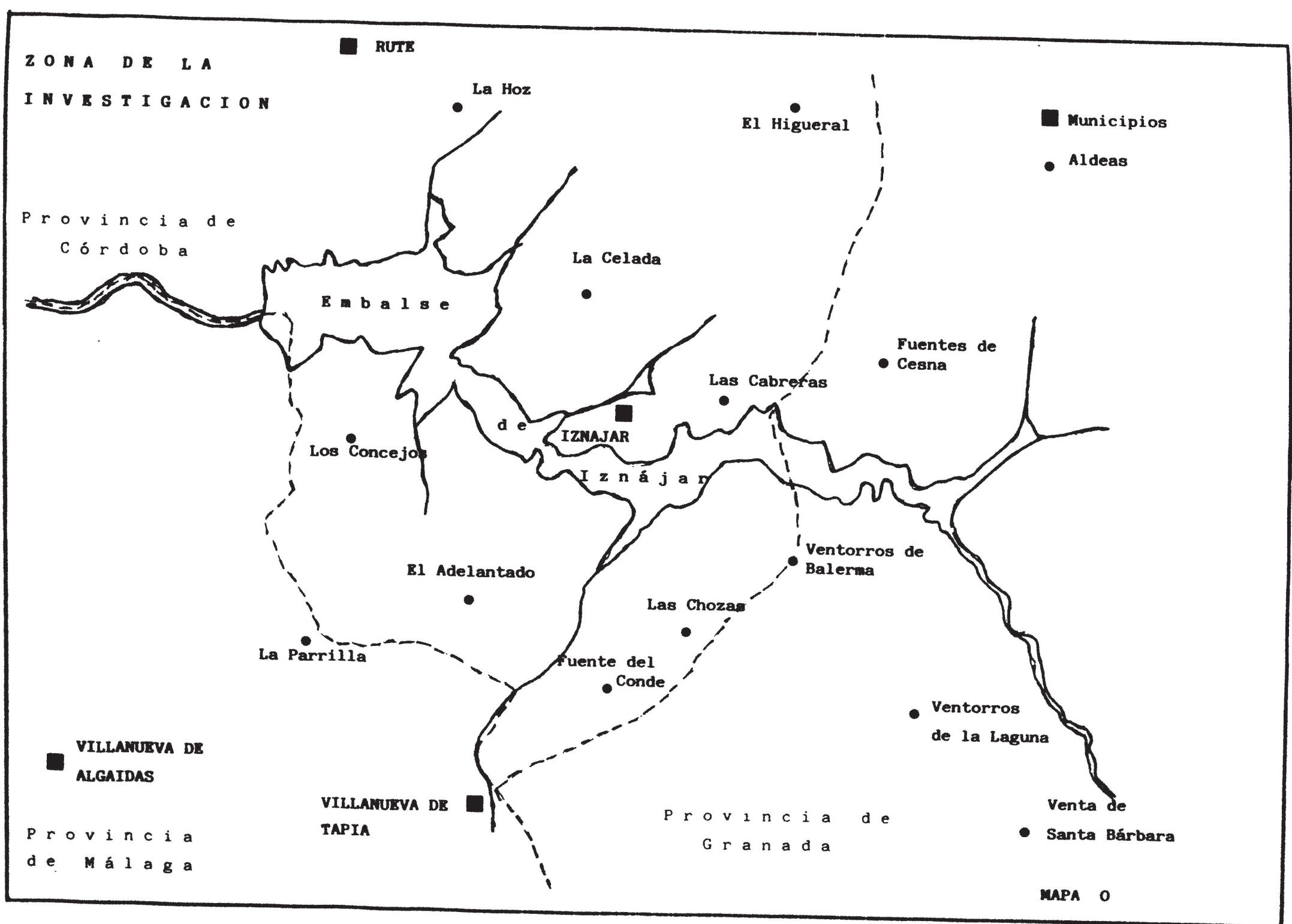


1. Cultivos ${ }^{12}$

\subsection{Secano}

bainiya f. 'vaina de las habas y de la veza'

Fernández-Sevilla, Léxico, 240: vaina y sus variantes (vainiya y otras) 'vaina de las legumbres' ocupan el $80 \%$ de las localidades encuestadas en el ALEA; vid. Uritani, Diminutivos, 214-215, para el predominio de -illo en el área central y oriental de Andalucía.

cabcabito m. 'vaina del garbanzo'

Cf. Alcalá, Voc. and. s.v. cascabitos, cascabuyo y cascarabito; FernándezSevilla, Léxico, 241: cascabito, en nueve puntos andaluces, y otras variantes cascabiyo, etc., son variantes patrimoniales del étimo latino CACCABUS 'olla' y del diminut. CACCABULUS 'puchero'.

garbanso de bena m. 'garbanzo blanco, tierno para el cocido, en el que se aprecian unas rugosidades a semejanza de venas'

Alcalá, Voc. and. s.v. garbanzo de vena: $\mathrm{m}$. El de gran tamaño y generalmente arrugado. (Torre del Campo, Jaén) «Te parecen pequeños estos garbanzos porque son garbanzos de vena: pero verás cuando cuezan»; Dicc. And., III, s.v. garbanzo. $2 / /$ de vena.

garbanso comunibta $\mathrm{m}$. 'variedad rojiza de garbanzo, menuda, que no se emplea en la cocina'. Se trata de una designación metafórica (comunista) basada en el 'color rojo', de la que no hemos encontrado documentación andaluza.

garbansa f. 'variedad de garbanzo de gran tamaño, muy blanca y sabrosa en el cocido'

12 Transcribimos los términos de forma aproximada, de acuerdo con las realizaciones más generales en el habla del treviño, e indicamos las variantes que se documentan en función de fenómenos como la aspiración /h/, el yeísmo o el seseo coronal (seseo cordobés, muy característico, como el de Baeza, aunque sin connotaciones socioculturales; ver CARrasco, Baeza, 84). Para conocer la fonética y fonología en el área del treviño, ver GALEOTE, Habla, 33-96; respecto de la aspiración /h/ < F- inicial latina conviene destacar que es un arcaísmo lingüístico rural en retroceso (cf. Mondéjar, Origenes, 203-210 y Andaluz, $\$ 7.2 .1-2)$; sobre el debilitamiento consonántico en la distensión silábica y la presencia /latencia de /-h/, ver VillenA, Vocalismo, 11-41. 
Toro, Voces s.v. garbanza: s.f. Garbanzo grande. «No ya de garbanzos, sino de garbanzas de su pueblo». (En Ángel Ganivet). García de Cabañas, Alpujarra, 55: garbanza. adj. Variedad de judías de semilla blanca.

rabpa f. genérico 'cereales'

Ver Alcalá, Voc. and., s.v. 2. raspa 'nombre genérico de los cereales que llevan aristas en la cáscara de sus granos'; Cabra-Vocab., s.v. raspa [rabpa] Cereales. Hablando de un terreno se dice «lo tuve de $r a^{b} p a »$, esto es, 'sembrado de cereales'; García de Cabañas, Alpujarra, 105, rahpa 'arista o filamento terminal de la cascarilla que envuelve el grano de trigo, de cebada y de otros cereales'; Fernández-Sevilla, Léxico, 147-148, trae entre las denominaciones traslaticias y ocasionales de la 'mies', raspa en La Puebla del Río (Sevilla).

semiya(s) f. pl. 'las legumbres: veza, habas, garbanzos'

Alcalá, Voc. and. trae semillería 'Conjunto de semillas' (Sevilla), con una cita donde semillería equivale, a nuestro juicio, a 'legumbres'; Fernández-Sevilla, Léxico, 44, n. 50: barbecho de semillas, donde el genérico semillas significa 'legumbres'.

\subsection{Regadío}

abinao adj. 'dícese del melón que adquiere un particular sabor agrio, por excesiva madurez o por casta'

Alcalá, Voc. and. s.v. avinarse: r. Tomar gusto ácido las frutas excesivamente maduras. Dícese especialmente del melón. "Estos melones se avinarán si no os los coméis».

asendría (acendría) f. 'sandía, Citrullus vulgaris'

Cf. Alcalá, Voc. and. s.v. asendría. f. Vulgarismo de sandía "Compré un melón y una asendria»; s.v. acendría f. Sandía. «Se comió una acendria entera»; también en Fernández, Priego, s.v. asendría. Ver ALEA, lám. 324, m. 334: Co 609 Iznájar, asendía y Gr 303 Algarinejo, asendria; DCECH V, 147, s.v. sandía: se trata de un arabismo cuya -r - se explica por analogía.

betoaya, betuaya f. 'la hortaliza, en general: pimientos, tomates, cebollas, pepinos, etc.' 
${ }^{20} \mathrm{DRAE}$ s.v. vitualla $* / / 2$. fam. Abundancia de comida, y sobre todo de menestra o verdura». En el área del treviño se ha debido de producir una especialización del término, junto con algunos cambios fonéticos de vitualla.

layo m. 'sabor agriculce de algunas frutas, especialmente la granada y la manzana' (expr. graná de layo, mansana de layo; tener buen layo).

Ver Chamorro, Derivados, layo 'dolor', 29-32; Toro, Voces, s.v. ignora el significado; Fernández, Priego, s.v. layo (De...): (Expr. adv.). Indica que algo está entre lo agrio y lo dulce [...]. Ej. Ebte granao eb durse, ese de layo y aqué(l) de diente-perro; cf. Galeote, Habla, 108 dienteperro.

pepinaca f. 'calabacín, variedad de calabaza alargada, que se asemeja al pepino, aunque es más gruesa'

El origen del término está, sin duda, en la base pepino con un sufijo femenino despectivo debido al influjo de calabaza. Alcalá, Voc. and. trae otras formas diminutivas de pepino: s.v. pepinico del diablo, pepinillo del diablo.

reculo m. 'melón o pepino menudo, tardío y de mala calidad'

Toro, Voces s.v. reculo (voz oída): s. m. Melón verde y chico; Alcalá, Voc. And. s.v. reculo: Objeto torcido en su base. U.t.c.s. «Ese pepino es reculo y amargará bastante».

\subsection{El olivo}

\subsubsection{El árbol (flor, fruto, partes, etc.)}

asituna, acetuna f. 'fruto del olivo, oliva'

Ver m. n. ${ }^{\circ}$ 1; Carrasco, Baeza, 153 asituna; Fernández-Sevilla, Léxico, 265 n. 46: «Se han registrado muchas variantes fonéticas, entre las principales: acituna (vulgarismo anotado por Cuervo), acetuna (es la forma usada por G. A. de Herrera); abituna, aceibtuna aparecen esporádicamente».

orabca f. (De hojarasca) f. 'hoja caída del olivo'

Cf. ${ }^{20} \mathrm{DRAE}$ s;v; hojarasca f. Conjunto de las hojas que han caído de los árboles; Martínez-Moya, Léxico, m. 36 «hojas secas caídas del árbol»: bojarasca se documenta en el occidente de la provincia de Jaén. 
MAPA 1

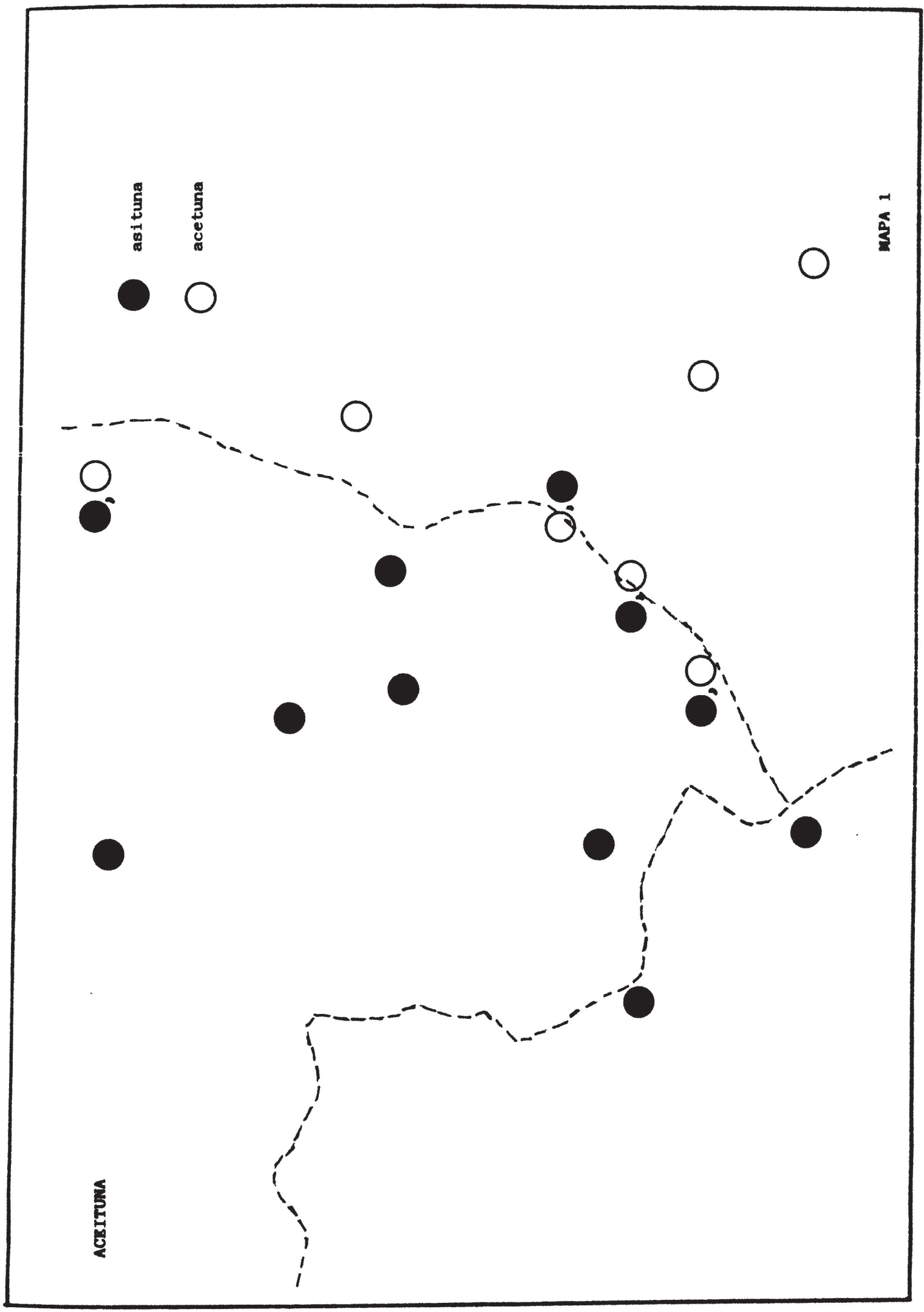


tarama f. 'támara, rama cortada del olivo o de cualquier otro árbol'

Cf. Alcalá, Voc. and., s.v. tarama: f. Támara, en Andalucía baja. «Lo mismo viene a decir éste: "Hazme buena cama y tápame con una tarama". Así llama la gente del campo a las támaras...» (Fernán Caballero) (trae más ejs.); s.v. taramal, m. Tamaral, terreno poblado de taramas o támaras. (Andalucía baja); Cabra-Vocab., s.v. tarama [taráma] Rama; s.v. entaramar [entaramal] Poner ramitas para sostener el tallo de las judías; y quitarlas, desentaramal; García de Diego, Etimologias, 406-410.

ALEA, lám. 327, m. 339 ramojo 'ramitas secas': Co 609 Iznájar, tarama; lám. 660, m. 720: tarama en Co 609, Gr 303 (Algarinejo) y Gr 500 (Salar); Martínez-Moya, Léxico, m. 28: támara 'rama seca' y támara 'rama seca en los árboles del monte', en puntos de la mitad oriental de la provincia jiennense.

coboyo m. 'cogollo, tallo principal, rama alta del olivo'. Vid. el mapa n. ${ }^{\circ}$ 2. Junto a esta designación se dan cogoyo, tayo 'tallo', copa 'copa del árbol' y guía (ver infra).

Alcalá, Voc. and., s.v. 1 cobollo, m. Cogollo, y creo que es más pura. «A esa lechuga le quitas los cobollos más verdes y aliñas lo demás»; s.v. cojollo, m. Cogollo o cobollo. "Yo quiero mucho a mis señores, y er que quiere la có, quiere los cojollitos de arreó...» [...]; ${ }^{20} \mathrm{DRAE}$, s.v. cobollo, $\mathrm{m}$. cogollo; s.v. cogollo, //2. Brote que arrojan los árboles y otras plantas; Cabra-Vocab., s.v. cojollo [kohoyo] Cogollo; Dicc. And., s.v. cobollo //2. m. Brote de árbol u otra planta; Toro, Voces, s.v. cobollo: Remero, esqueje. En la prov. de Jaén, cobollos: 'parte alta del olivo' (m. 15) y 'hojas y tallos que caen en el tendal al varear' (m. 79), Martínez-Moya, Léxico.

Cf. Alcalá, Voc. and., s.v. jcojollo!; lo mismo en Fernández, Priego, s.v. cojoyoh.

guia f. (lo mismo que coboyo, vid. supra).

Ver mapa n. ${ }^{\circ}$ 2. Cf. Martínez-Moya, Léxico, m. 11, 36: guía 'pie central del plantón' en Guarromán, Santiago de la Espada y Alcalá la Real; m. 58: guiar 'poda de formación del olivo joven' en Jódar y Porcuna; Alcalá, Voc. and., s.v. 3 guia: f. En la frase "Quedarse en las guías», no crecer un árbol lo debido. Se extiende a personas y animales jóvenes débiles o delgados; Cano, Osuna, 55-56: dar (la) guia 'cortar los brotes y ramas bajas para dirigir el crecimiento del árbol'. 


\section{MAPA 2}

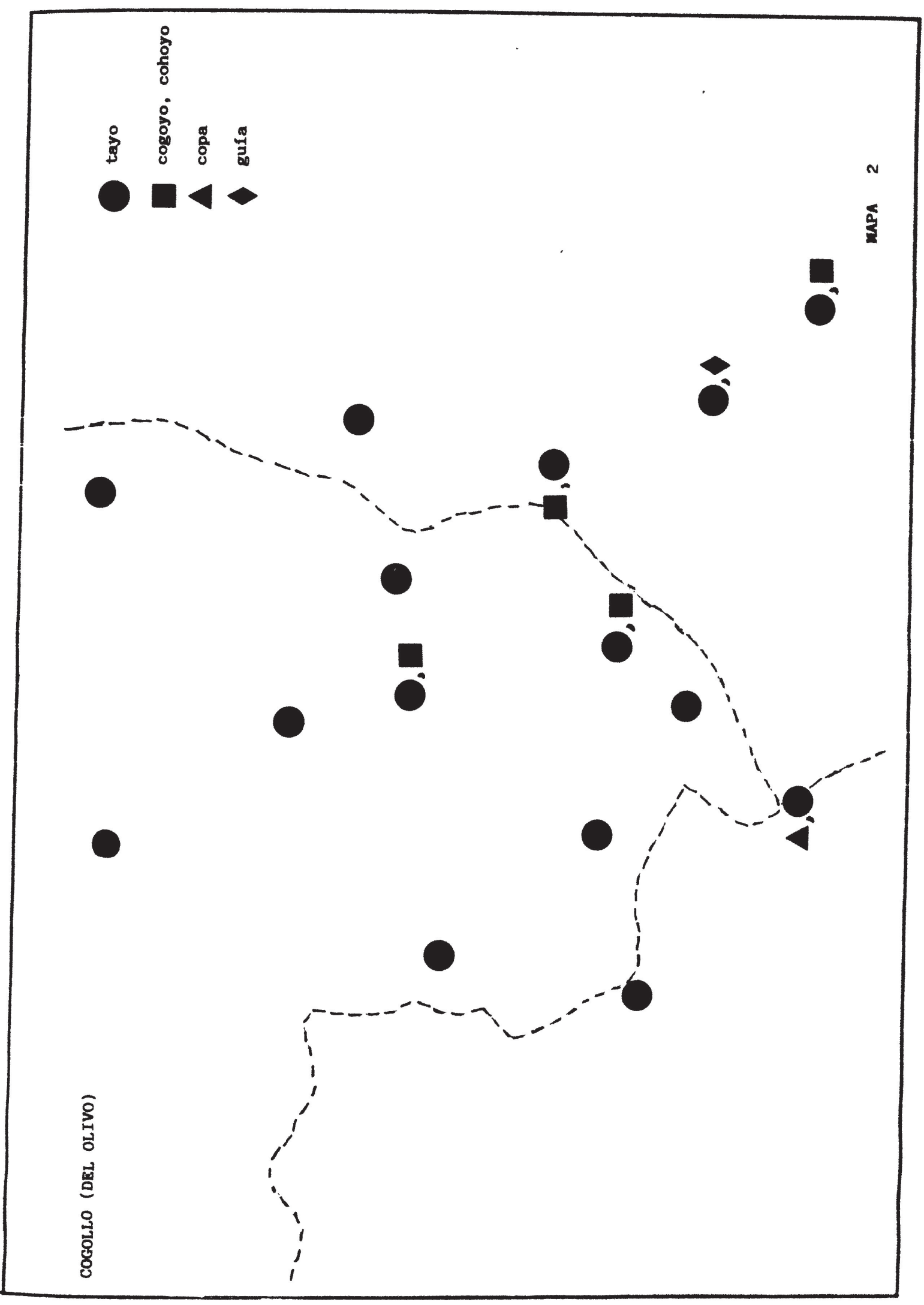


ebpoba(r) tr. 'caerse la flor del olivo'.

Ver Alcalá, Voc. and. s.v. despojar tr. Caer la flor del olivo dejando el cañamón en él. «Hogaño despojaron bien los olivos»; s.v. despoje m. Época de despojar los olivos.

Martínez-Moya, Léxico, 201 y m. 42 «caerse la flor del olivo»: despojar, espojar en puntos de Jaén, por especialización semántica.

talón, entalonao m. 'yema, primer brote de la formación del fruto'.

Martínez-Moya, Léxico, 201, m. 39 'yemas': talón (en la zona de las Subbéticas) 'yemas' es una metáfora antropomórfica. Cf. Alcalá, Voc. And. s.v. 2 talón $\mathrm{m}$. 'Cepa de la rama del olivo'.

\subsubsection{Variedades}

chorrúo adj. 'variedad de olivo de grandes ramas colganderas' (lo mismo que bardú, barropo, tachuno y yorón).

Ver mapa n. ${ }^{\circ}$ 3. Se documenta en La Celada y en Los Concejos de Iznájar; Alcalá, Voc. and., s.v. chorrúo, rrúa adj. Olivo de hoja larga y fina de color muy verde, cuyas ramas penden como las del sauce// Aceituna propia del chorrío, de forma redonda; Ortega, El Sur, 169: "bardúo o chorrio en Cabra".

bardúo (De baldudo) adj. 'variedad de olivo' (lo mismo que chorrúo, harropo, tachuno y yorón).

Ver mapa n. ${ }^{\circ}$ 3. El ${ }^{20} \mathrm{DRAE}$ s.v. baldudo 'con faldas amplias'; Alcalá, Voc. and., s.v. balduo, úa. adj. Olivo y aceituna chorrúos «Los olivos balduos se defienden de las heladas mejor que los otros.» «¿Cómo confundes la aceituna baldía con la de cornezuelo?»; s.v. haldar m. Rama costera de un árbol; s.v. baldares m. pl. Ramas bajas del olivo. Harapos, bajeras. (Torreperogil, Jaén); s.v. jarduco adj. Nombre que se da en la provincia de Córdoba a una variedad del olivo. (Con un testimonio referido a Cabra); Cabra-Vocab., s.v. jardía [hardía] Una clase de aceituna; Dicc. And., III s.v. hardear. «tr. Ordeñar los olivos. Voz de Málaga». En la prov. de Jaén (zona de la Cordillera Subbética) haldares o baldar 'alabes', Martínez-Moya, Léxico, 166-167 y m. 16; En murciano haldar, baldares 'ramaje que cuelga hasta la tierra', Muñoz, Dialectologia, 76. 
MAPA 3

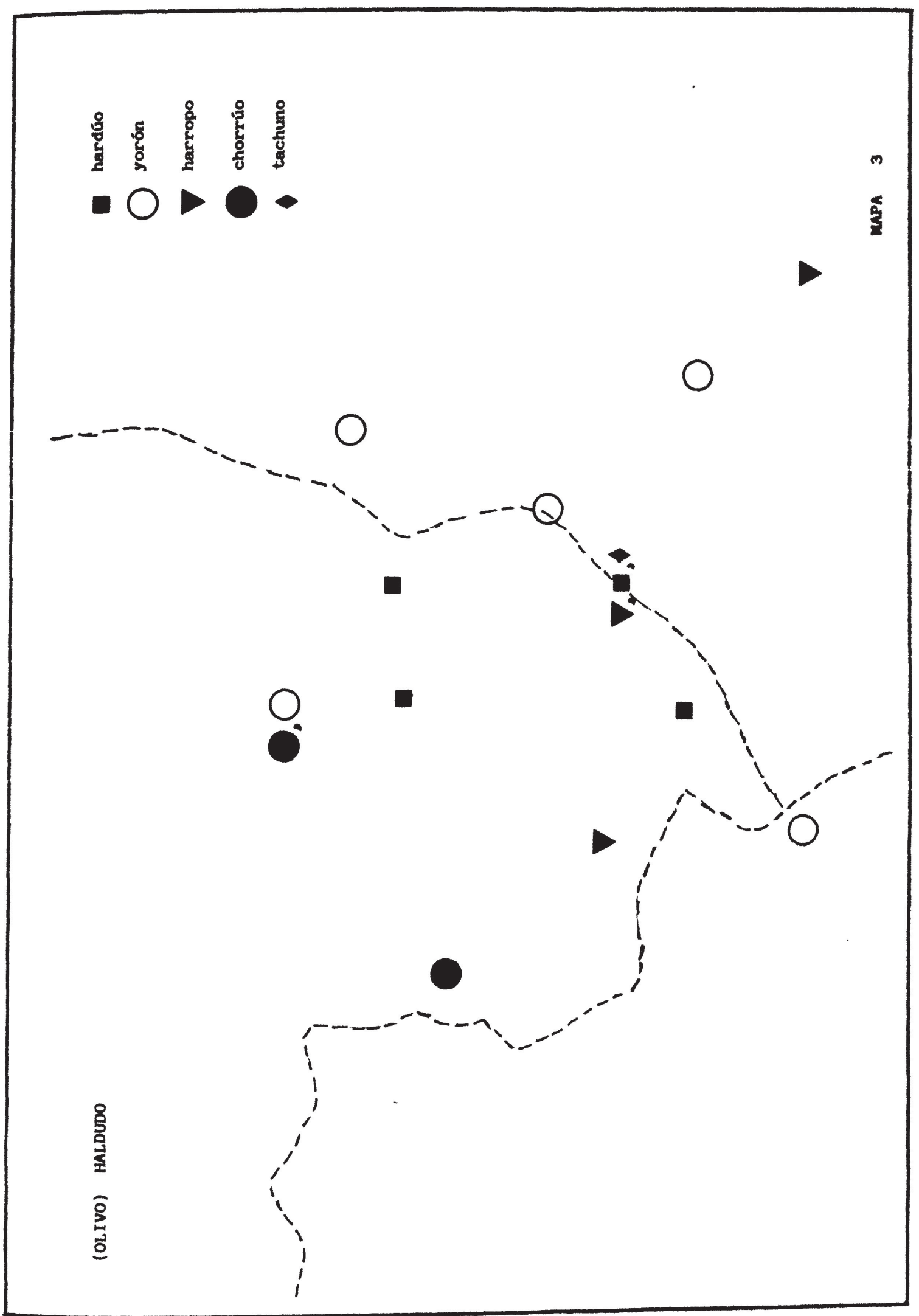


barropo adj. (lo mismo que chorrúo, hardúo o yorón, vid. s.v.).

Ver mapa n. 3. A esta acepción de 'casta de olivo con grandes ramas largas, haraperas' se habrá llegado por un desplazamiento desde el mundo animal: (cabra) barropa '(cabra) de pelo largo'; Cf. Cabra-Vocab., s.v. jaropa Una clase de aceituna que es buena para sacar aceite (Doña Mencía).

picúo - ía adj. 'Variedad de olivo y de aceituna que termina en pico. Olea Europea Columella, M. R.'.

Ortega, El Sur, II, 169, 177: olivo picudo de «hojas grandes, anchas, color verde brillante intenso por el haz y grisáceo por el envés». Cf. Alcalá, Voc. and. s.v. picudal 'adj. Casta del olivo. U.t.c.s.'; s.v. picuda adj. Aceituna que termina en pico y que no es la de cornezuelo (con una cita de J. Valera). Martínez-Moya, Léxico, 143-144 picúa; 145: picual, variedad dominante, de alto rendimiento graso, aceituna grande que acaba en punta -de ahí su nombre-, hojas anchas, etc.; Cano, Osuna, 49, 52: asituna picuia o tetúa.

tachuno adj. 'variedad de olivo' (lo mismo que chorrúo, hardúo o yorón, vid. s.v.). Ver mapa n. 3.

Cabra-Vocab., s.v. tachuno: Dícese del olivar que tiene todos los olivos de la misma clase; Martínez-Moya, Léxico, no lo documentan en Jaén, ni lo trae Alcalá, Voc. and.

yorón adj. 'dícese del olivo de grandes ramas' (lo mismo que chorrío o hardio, ver s.v.).

Por semejanza con el sauce llorón, sin duda; Cano, Osuna, 49, 52: llorona, yorona 'tipo de aceituna larga y de hoja larga', «lo cual fue la base para la creación de la metáfora con que se la designa: compárese con el sauce llorón».

\subsubsection{Labores del olivar}

solea(r) tr. 'recoger las aceitunas que se cayeron del olivo antes de varearlo'. (También se usa soleo, sust.)

Alcalá, Voc. and. trae soleo: m. Recolección de la aceituna caída del árbol; Moliner, Diccionario s.v. soleo (Andalucía) Recogida de la aceituna caída naturalmente al suelo. 
solero $\mathrm{m}$. 'espacio de tierra que cubre el vuelo del olivo'; en la expr. hacer los soleros 'allanar la tierra y rozar la yerba para recoger las aceitunas'.

Ver Martínez-Moya, Léxico, m. 71 suelo: está muy extendido, en tres puntos: hacer suelos 'alisar el terreno para la recogida del fruto'; Cano, Osuna, 61: hasé lob suélo: 'allanar la tierra, quitando la hierba y terrones para que no se pierda la aceituna'.

frailea $(r)$ tr. 'cortar todas las ramas del olivo y dejar únicamente el tronco para que retoñe'.

${ }^{20} \mathrm{DRAE}$ s.v. frailear (De fraile) tr. And. Cortar las ramas del árbol por junto a la cruz; Alcalá, Voc. and., s.v. frailear tr. 'Afrailar, podar un árbol no dejando más que el tronco'; Cabra-Vocab., s.v. fraile El árbol después de podado; Ortega, El Sur 168, 186: la poda de renovación del olivo hojiblanco «responde a la técnica del "afrailado" o poda en cabeza»; Cano, Osuna, 60: fraileá o hasé er fraile. Cf. Alcalá, Voc. and., "Afrailar la parva» (s.v. 3 parva); también s.v. frailera adj. Variedades de aceituna y de ciruela.

\section{LA RECOLECCIÓN}

\subsection{La siega}

gabiya f. 'porción de mies sin atar, normalmente de habas y de veza'. La gabiya de habas se hace de dos pabeas gualdrapeadas y la de veza en forma de ovillo.

Cf. Alcalá, Voc. and., s.v. gavilla 'conjunto de haces de mies' y s.v. gavillas, con otro sentido en Málaga; Carrasco, Baeza, 149 gaviya 'gavilla' 'tres manadas de mies'; Fernández-Sevilla, Léxico, 152-153 gavilla 'gavilla de mies' en el centro y mitad oriental de Andalucía. Pavea 'gavilla' en el centro y occidente andaluces. Ver ALEA lám. 40, m. 44 gavilla 'montón de manojos sin atar': Co 609 pabea.

há(b) $\mathrm{m}$. 'varias pabeas (2-4) de cereales gualdrapeadas, que se atan con un vencejo' 'conjunto de manojos de garbanzos, matalahúva, leña, etc. que se atan con cuerdas de esparto, juncos o gayomba'.

La diferencia entre el há(b) y la gabiya en el treviño está en que el uno 'se amarra con vencejo' y la otra no. Ver ALEA m. 45 baz 'gavilla o gavillas atadas': Co 609 háh. En ciertas ocasiones, varias gabiya(s), a su vez, pueden formar un $h a(z)$ para facilitar el acarreo o barcina a la era. 
Fernández-Sevilla, Léxico, 154 «en Andalucía la voz normativa baz está muy difundida; sólo gavilla parece hacerle competencia en el centro y oriente»; 155 «Por su parte haz también ha especializado su significación en algunos puntos [...] En Ca 601 y 602 há es sólo el de trigo; en Ma 408 bá es el de leguminosas, y, por último, en Gr 514 bah sólo se refiere al de garbanzos»; Carrasco, Baeza, 149 ha(z) 'conjunto de tres gavillas atadas'.

pabea f. 'conjunto de manojos de mies (cereales).

Cf. Alcalá, Voc. and. s.v. pavea 'Haz de monte o de mies. De ésta, seis gualdrapeadas hacen una gavilla'; pabea 'Gavilla de cereal' (Alcalá de los Gazules, Cádiz); Cabra-Vocab., s.v. pavea [pabéa] Gavilla de mies de cuatro o cinco puñados (Doña Mencía); «carro de paveas» es una 'hilera de gavillas'; Fernández, Priego, s.v. pavea Gavilla sin atar; Fernández-Sevilla, Léxico, 150: pavea 'manojo de trigo' en Málaga y Cádiz con mayor frecuencia que en Huelva, Sevilla y Granada; 153: pavea 'gavilla' localizada en el centro y occidente de Andalucía. Originariamente es un portuguesismo; Alvar, Atlas, $\int$ 63.1.1.; pasó a las Islas Canarias, Llorente, Comentario, 309 310, n. 82.

\subsection{Barcinar}

balsina(r), barsina(r) tr. 'transportar las mieses a la era'.

${ }^{20} \mathrm{DRAE}$ s.v. barcinar «(And.) Coger las gavillas de mies, echarlas en el carro y conducirlas a la era»; Alcalá, Voc. and. s.v. barcinar intr. Conducir las gavillas de mies a la era. Cf. Dicc. And., III, s.v. harcinar: tr. Agr. Transportar la mies en carro; Fernández-Sevilla, Léxico, 170 «es voz típicamente andaluza. Abunda en el centro de la región desde donde irradia hacia las áreas marginales»; Carrasco, Baeza, 149: acarrea(r) y barsina(r); «barcinar es canario y no sólo andaluz», Alvar, Atlas, $\$ 58.3$. Para el tipo de angarillas empleado, véase Galeote, Habla, 110-111 y las ilustraciones de las págs. 238-239.

galbera, garbera f. 'montón de haces o gabiyas cerca de la era' (raramente sobre el rastrojo).

Ver ${ }^{20} \mathrm{DRAE}$ s.v. garba y garbera; Dicc. And., III, s.v. garba de heno. f. Pajar de heno; s.v. garbera de yerba. f. Pajar de heno; ALEA lám. 53, m. 58 bacina Co 609 Iznájar, [gar'béra].

Millán, Aragonesismos, 411-412: garbera y otras formas emparentadas se dan en una amplia zona de la Andalucía oriental, central y occidental. 
Los diccionarios aragoneses registran garbar, garbear, garba, garbera, etc.: y el ALEANR localiza garbera 'hacina: montón de mies en la era'. Cf. Soriano, Vocabulario, s.v. garbera, galvera. Fernández-Sevilla, Léxico, cree que garbera 'montón de haces' < garba y que esta palabra debió llegar con los conquistadores y repobladores aragoneses, 166. "Comparando el número de documentaciones de garbera 'hacina' con las de garbera 'tresnal' se llega a la conclusión de que la primera debe ser la más antigua, por encontrarse más extendida», 189-190.

García de Cabañas, Alpujarra, 56: garbera s.f. 'Rimero, montón de cosas colocadas unas sobre otras'. Alcalá, Voc. and., s.v. garbesada f. Abundancia, copia, cantidad (prov. de Almería). «Este año hubo garbesá de tomates».

\subsection{Trillar las mieses}

emparba(r) int. 'extender los haces o gavillas de mies en la era para formar la parva'.

Ver ${ }^{20} \mathrm{DRAE}$, s.v. emparvar tr. Poner en parva las mieses; FernándezSevilla, Léxico, 192: «Luego tiene lugar la operación de emparvar, es decir, de formar la parva. Los campesinos, provistos de hoces y horcas, van rompiendo los ataderos y esparciendo la mies, que queda así revuelta y desordenada»; 193: emparvá(r), formado sobre el sustantivo parva, se documenta en más de cien puntos desde Huelva a Almería; cf. García de Cabañas, Vocabulario, 49: emparbáo s. m. Parva, mies extendida en la era y dispuesta para la trilla; Carrasco, Baeza, 152, parva.

entama(r) tr. 'echar tamo en la era (empedrada) antes de emparvar, para facilitar la trilla'.

Cf. ALEA lám. 51, m. 56 (etnográfico) y la adición al mapa «Instrumentos para endurecer el piso de la era»: entamar (igual en Dicc. And., II, s.v.) en puntos de Huelva, Sevilla, Cádiz, Córdoba y Málaga es la forma de preparar las eras terrizas en el treviño; entamar, con otra acepción, en Alcalá, Voc. and.

oriyá f. 'el extremo de la parva de mies, que se remete con la horca o el bieldo durante la trilla'.

Alcalá, Voc. and. s.v. orilla f. En la frase "Meter las orillas" ... proviene de la faena de remeter los extremos de una parva de mies, que el trillo esparció; ALEA, lám. 54, m. 59 Emparvar, en Gr 504: la(s) orilla(s) 'espiga que queda fuera de la parva'. 


\subsection{Limpieza del grano}

Abenta( $r$ ) tr. 'arrojar al viento la mies trillada para separar el grano de la paja'.

Fernández-Sevilla, Léxico, 212, documenta aventar en el occidente andaluz hasta el límite de Córdoba y Jaén; 213, 446: aventar y ablentar se reparten el dominio andaluz; cf. Alcalá, Voc. and., s.v. ablentar; Carrasco, Baeza, 151, ablenta(r); Soriano, Vocabulario, s.v. ablentar.

envasa( $r$ ) tr. 'poner el grano aventado en sacos o costales'.

Carrasco, Baeza, 147: envasa(r); Fernández-Sevilla, Léxico, 226-228: «la voz más difundida es la castellana envasar, [...] que se extiende por toda la región y cuyas documentaciones representan el $57 \%$ del total».

gorbe(r) (la parva) tr. 'volver la mies cuando se está trillando para que se desgranen las espigas o vainas'.

Lo más normal es que los labradores le den la primera güerta con la horca, la segunda con el biergo y la tercera con la pala (de madera). Ver Galeote, Habla, 110 s.v. biergo, 111 s.v. horca y 233 (fotografía de las tres herramientas); Cf. Carrasco, Baeza, 152, volve(r) (la parva); ${ }^{20} \mathrm{DRAE}$ s.v. volver. tr. Dar vuelta o vueltas a una cosa.

$p e ́(b)$ 'montón alargado de grano en la era, después de aventado'.

${ }^{20}$ DRAE s.v. 1 pez // 3. fig. Montón prolongado de trigo en la era u otro cualquier bulto de la misma figura; Carrasco, Baeza, 152, pe(z); Fernández-Sevilla, Léxico, 205-206: «pez frecuente en Córdoba, Jaén y Granada»; 218, se trata de una animalización por la forma alargada del 'montón de grano'.

piquera 'Ventana del pajar, por donde se mete la paja'.

${ }^{20}$ DRAE s.v. piquera f. Agujero o puertecita que se hace en las colmenas para que las abejas puedan entrar y salir.

Alcalá, Voc. and., s.v. 5 piquera f. Hueco por donde se mete la paja en un pajar. "Con uno que haya en la piquera para subir la paja es bastante». Cf. Fernández-Sevilla, Léxico, piquera en el regadío, 279, 286, 289.

tamera f. 'Lugar donde cae el tamo, durante el aviento'.

Alcalá, Voc. and., s.v. tamero $\mathrm{m}$. Sitio donde cae el tamo de la paja al aventarla. Soviento. "Todos los días debéis limpiar bien el tamero»; s.v. 
soviento 'id.'; Fernández-Sevilla, Léxico, 224-225: tamo, general en el dominio andaluz; soviento en Huelva, Sevilla, Cádiz, Jaén y Granada; cf. Carrasco, Baeza, 152, tamo.

\section{Plantas silvestres}

abuma f. 'hoja de la retama'.

Se emplea para preparar la bilma 'bizma, cierto emplasto de abuma, majada con sal, para curar las patas de las cabras'. Cf. Alcalá, Voc. and., s.v. bilma y ${ }^{20} \mathrm{DRAE}$, s.v. bizma y bilma.

Garulo, Arabismos: aljuma 'retama seca' 'rama de la retama' 'leña menuda que se echa a la lumbre' 55, n. 111 bis («aljuma es voz típica del oriente andaluz, de influencia murciana»), 59, 85, 183-184. Cf. Alcalá, Voc. and. s.v. 1. aljuma f. Pimpollo o tallo nuevo de las plantas; s.v. 2. aljuma f. La hiniesta hecha ya escobas; Pizarro, Pedroches, s.v. escoba de ajuma: f. Escoba de hiniesta; en Osuna, búbma 'extremos del ramón del olivo', quizá sea la misma voz, en contra de lo que piensa Cano, Osuna, 46.

alfilerito, arfilerito m. 'Alfiler. Erodium cicutarium'. (El diminutivo está lexicalizado); ver Uritani, Diminutivos, 215-216, para el sufijo ito, difundido en la Andalucía occidental (Córdoba y Málaga son áreas de transición).

Cf. Font Quer, Dioscórides, 417-418: Erodium cicutarium, L'Heritier, $\mathrm{Al}$ filerillo de pastor. Sinonimia castellana: alfilerillo, alfiler, aguja de vaquero, etc.; Güel, Malas hierbas, 109, 192, 200; Pizarro, Pedrocbes, 121, s.v. alfilerillo de pastor; Alcalá, Voc. and., s.v. alfilericos; Criado, Estudio, s.v. alfilericos.

almirón $\mathrm{m}$. 'Diente de león (Taraxacum officinale)'. Por almirón real es conocida otra planta: el 'zurrón de pastor' (Capsella bursa pastoris).

${ }^{20} \mathrm{DRAE}$ s.v. almirón And. amargón; Alcalá, Voc. and., s.v. almirón: 'm. Amargón, hierba'; Font Quer, Dioscórides, 868-870: «(Taraxacum officinale Weber). Diente de león. Sinonimia castellana: taraxacón, achicoria amarga, amargón, almirón [...]».

cuidaito $\mathrm{m}$. 'Calendula arvensis $\mathrm{L}$., de la familia de las compuestas'.

Güel, Malas Hierbas, 74, 190, 210. Calendula arvensis L. Maravilla de los campos; Font Quer, Dioscórides, 833-834: «Sinonimia castellana: maravilla de los campos, caléndula silvestre, bierba del podador, hierba va- 
quera, [...]». Ibidem, 832: Entre la sinonimia portuguesa de la Calendula officinalis L. Maravilla encuentro: cuidados. En el ALEA lám. 292 m. 296, la margarita (Bellis perennis) se denomina en Co 609 Iznájar cuidaito del campo, pero nosotros hemos documentado mansaniya de borrico, como en Alcalá la Real (Jaén).

bamapola, banapola f. 'Papaver rhoeas, amapola'. En adultos y ancianos de Villanueva de Tapia, Las Chozas, Ventorros de Balerma, Ventorros de la Laguna, Las Cabreras, La Celada y El Higueral.

Cabra-Vocab., s.v. janapol [hanapó] Amapola (Doña Mencía); ALEA lám. 291, m. 295 Amapola: Co 609 Iznájar [hanapóla], con aspirada también en lugares de Granada y Jaén; DCECH s.v. amapola 1.a doc. hamapol h. 1400, hamapola en Nebrija. «Se pronunciaba con $b$ aspirada: jamapola en el malagueño Fernández de Ávila».

miso m. 'alpiste vano, silvestre'.

El miso es la siguiente planta descrita por Güell, Malas bierbas: "Phalaris brachystachys, Link (Gramíneas). Alpiste vano, alpistera, rabo de cordero», 195, 200. «Espigas cortas y ovales. Planta anual común en los campos de trigo de Andalucía», 161. Probablemente por su parecido con el "Polipogon monspeliense, Desf." (Gramíneas), Mijo silvestre (Güell, Malas bierbas, 210; «Espigas con aspecto algodonoso. Planta anual. Secanos y en los regadíos poco cultivados, en verano», 16), los hablantes confundieron las dos gramíneas y se produjo, a nuestro juicio, un desplazamiento designativo, conservándose hasta la actualidad el probable arcaísmo miso $<$ mijo [mížo] < MILIU $(M))$, por el trueque de sibilantes, entre la apicoalveolar fricativa sonora / $\dot{z}$ y la prepalatal fricativa sonora $/ \check{z} /$, lo mismo que perviven tiseras 'tijeras', tisereta 'cortapicos' (en ancianos del treviño) frente al castellano tijeras, tijereta ${ }^{13}$. El ALEA, lám. 290, m. 294 «Llantén (Plantago) 'una planta mala que sale por el trigo y se parece al alpiste que comen los canarios' trae en Co 609 Iznájar [mizo] [?]».

Ver mapa n. 5 "Alpiste vano" para la distribución geográfica de miso (su variante niso) y arpibtelera.

13 Alonso, Trueques, 7-8, «la lengua general los rectificó todos menos tijeras, heregia, sanguijuela y los topónimos». 
MAPA 4

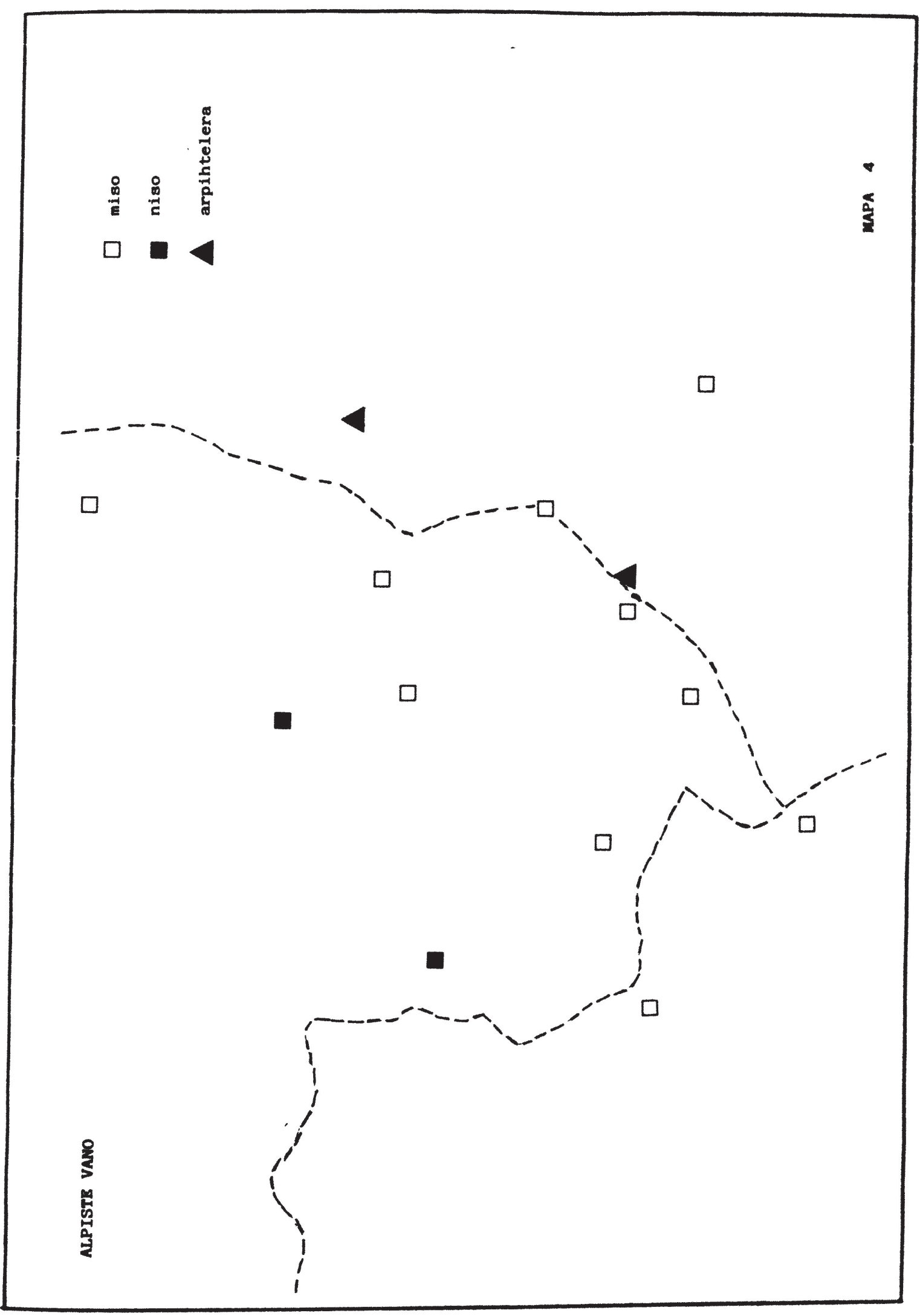




\section{APEROS Y HERRAMIENTAS}

barsón, farsón m. 'barzón' 'aro de cuero para enganchar el rabero al ubio' (Villanueva de Tapia, Las Cabreras, La Celada, El Higueral y Las Chozas).

La forma farsón es un singular explicable, sin duda, por regresión a partir del plural los barzones $>$ lofarsqne(s) $>$ el farsón, donde el grupo $-s+b->\mathrm{f}$ - por fonética sintáctica. ALEA m. 124 barzón: en Co 609 el barsón es "de cuero". Según Fernández-Sevilla, Léxico, 391, «en Andalucía oriental (Granada y Almería) aparece, en 25 puntos, una forma plural barzone(b) que casi siempre hace referencia al conjunto 'barzón + mediana'».

Cf. Alcalá, Voc. and., s.v. barsón; Carrasco, Baeza, 143, barsón; Fernández-Sevilla, Léxico, 391: «Barzón se presenta con regularidad casi absoluta en el Centro y Oeste de Andalucía».

brabán $\mathrm{m}$. 'arado de acero de grandes dimensiones, arrastrado por el tractor, que hace una labor muy profunda'.

No lo encuentro en el ${ }^{20} \mathrm{DRAE}$; Alcalá, Voc. and., s.v. brabán 'm. Agric. Clase de arado que hace labor muy honda. "Con brabán voy a labrar todo el cortijo»'. Puesto que antiguamente había en el treviño un tipo de brabán 'arado grande' del que tiraban las bestias, debe tratarse de un nombre viejo aplicado a un objeto nuevo. Se ha creado un derivado brabanear arar con brabán'. Ver Fernández-Sevilla, Léxico, 67, grabaneal.

Cf. Carrasco, Baeza, 141, s.v. brabán arado de hierro de grandes proporciones compuesto de dos rejas'; Moliner, Diccionario, s.v. 'arado moderno en Burgos'; Millán, Aragonesismos, 409, considera brabán como aragonesismo en Andalucía (ALEA, m. 9: grabanear 'roturar' y meter un grabán 'meter un arado en un terreno que está sin trabajar' en dos puntos de Jaén; m. 18 grabanear 'barbechar' también en Jaén).

chapulina f. 'azada, herramienta de pala ancha para cavar la tierra'.

Ver Galeote, Habla, 110 s.v. (a)sá, (a)zá, (a)saíya; 111 legona; 112, s.v. soleta, zoleta; y espec. m. 33 (p. 216) y su correspondiente comentario cartográfico (p. 158). En el ALEA lám. 91, m. 95 azada encuentro chapulina en Ma 402-404, 406 y 408; Alcalá, Voc. and. trae chapuar (en Estepa). Vaquero, Léxico, 259-260, chapudiar (variante de chapodar) y chapodiar en Puerto Rico con el valor de 'rozar', 'limpiar el terreno', que pueden estar relacionados con chapulina; Fernández-Sevilla, Léxico, 303 cree que chapulina, emparentada con zapa, procedería del diminutivo con palatalización y africación de la inicial; cf. también Alvar, Atlas, $\$ 24$, n. 139 y $\$ 60.2 .4$ para la etimología. 


\section{LOS ANIMALES}

\subsection{Rasgos externos}

\subsubsection{Color}

habao, bá adj. Lo mismo que norigao, gá, pero es designación más antigua (ver infra s.v.).

Toro, Voces trae jabado, a; Soriano, Vocabulario, s.v. jabado, da. «adj. Se dice de las aves de corral, en especial de los gallos ingleses, que tienen las plumas de dos o tres colores y como formando escamas».

norigao, gá adj. 'lorigado, -a, dícese del gallo y de la gallina de plumas blancas y negras, mezcladas en forma de escamas'. Es denominación más reciente que habao, bá y más extendida. También hemos encontrado acuquiyao, yá con esta acepción, por cierta semejanza con el plumaje del cuquillo 'cuco'. Es un caso más de polimorfismo léxico.

Alcalá, Voc. and., s.v. lorigado, da 'adj. Gallo o gallina cuyas plumas tienen los colores formando redondeles como los de una loriga'.

cárdena adj. 'Se aplica a la cabra de pelaje blanco y negro, mezclados'.

Cf. ${ }^{20} \mathrm{DRAE}$ s.v. cárdeno, na //2. Dícese del toro cuyo pelo tiene mezcla de negro y blanco.

oribcana adj. (De orejicana) 'Dícese de la cabra con las orejas canas'.

Cf. ${ }^{20}$ DRAE s.v. orejisano, estructura semejante, aunque con otro sentido.

\subsubsection{Otras características}

harropa adj. 'Dícese de la cabra de pelo largo'.

Lo mismo en García de Cabañas, Alpujarra, 62, harropa; Vid. ${ }^{20} \mathrm{DRAE}$, s.v. jarropa adj. 'Se dice de la res cabría de pelo castaño tostado'; Moliner, Diccionario, s.v. jarropa (adj.) (Voz poco usual) Se aplica a la cabra de pelo castaño; ver supra s.v. harropo aplicado al reino vegetal (olivo harropo). 


\section{MAPA 5}

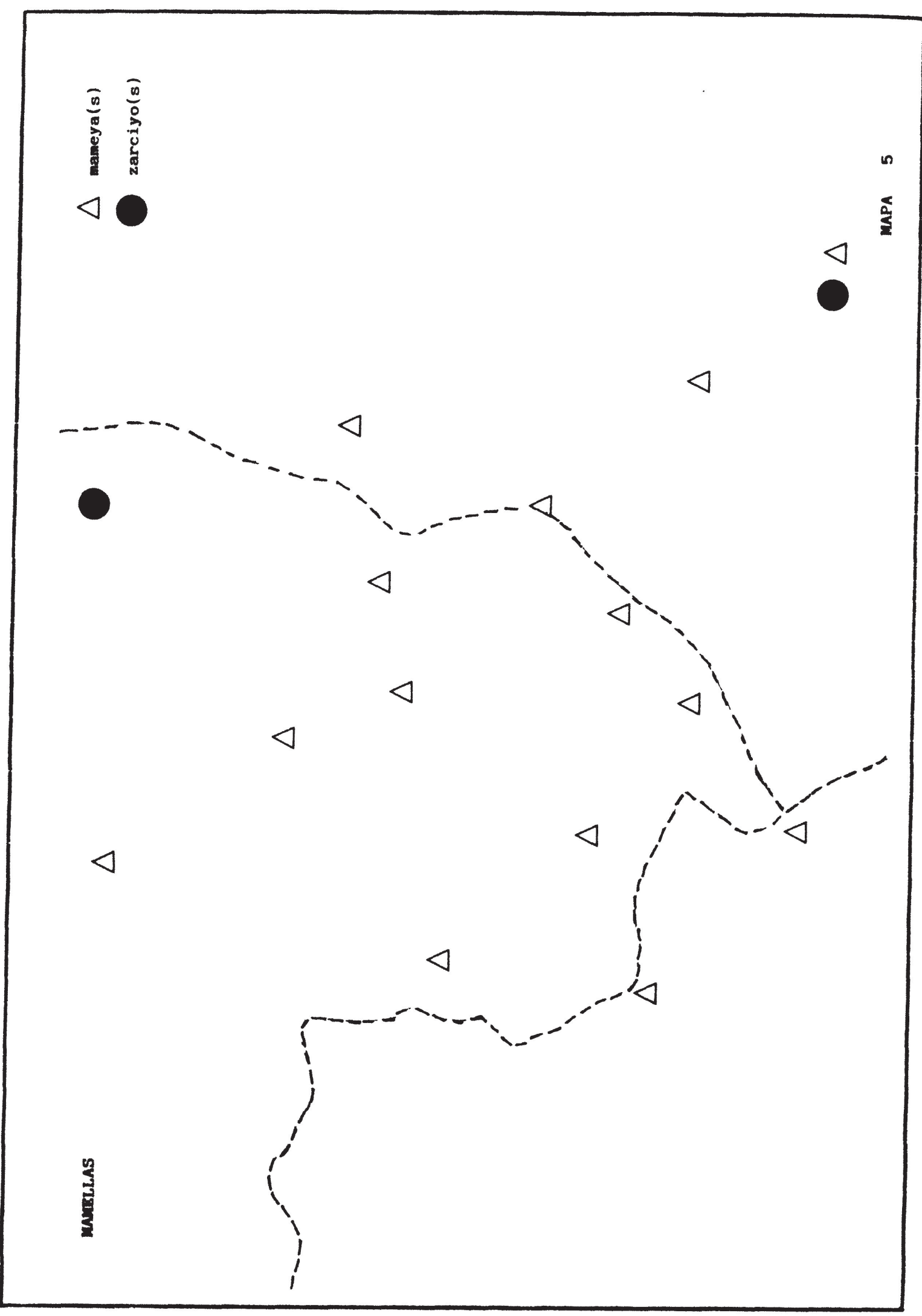


mameya(s) f. pl. 'mamellas, apéndices carnosos del cuello de algunas cabras', también denominadas zarciyo(s) en dos localidades, ver mapa n. 5 .

Cf. ALEA, lám. 506, m. 535 Co 609 Iznájar: mamella(s); Navarro, Voces, 111, zarcillos 'mamellas' «constituye un área uniforme que comprende las provincias occidentales, además de Córdoba, y, de ahí irradia hacia las localidades del resto de la región»; no lo recoge el DRAE ni Alcalá Venceslada.

\subsection{Animales del campo}

\subsubsection{Mamiferos}

fóyiga f. 'huella, rastro que deja la zorra por donde pasa'.

Ver Alcalá, Voc. and., s.v. fólliga «f. Huella. Se dice, generalmente, de las que deja el animal salvaje. ¿De fuélliga, huélliga?» [con extensas citas textuales]; Dicc. And., III, s.v. fólliga; Salvador, Cúllar-Baza, s.v. huéllega 'excremento de caza menor'; lo mismo en murciano, Soriano, Vocabulario, s.v. fóllega.

\subsubsection{Aves}

cubá f. 'cogujada. Galerida cristata'.

ALEA lám. 392, m. 409 cogujada: Co 609, cubá; Gr 303 Algarinejo, beheta, cubá. La forma vejeta se da en Jaén y sur de Córdoba, lo cual explica su distribución geográfica en el mapa n. ${ }^{\circ} 6$; para el área andaluza del sufijo -ete ver Uritani, Diminutivos, 219-220; sobre vejeta y su inclusión en el DRAE por mediación de J. Valera, ver Salvador, Lexicografía, 56. También Navarro, Voces, 110-111: vejeta es designación metafórica. Cfr. García Mouton, Nombres, 189-197, para este tipo de denominaciones populares.

cardereto, -ijo m. 'Carbonero común. Parus major'.

Alcalá, Voc. and., s.v. caldereta f. Pájaro pequeño (Loja, Granada); s.v. carbonerillo m. Azabache, pájaro (Prov. de Málaga); ver Mondéjar, Aguzanieves, 292-293, para las confusiones de la 'aguzanieves' con el carbonero o berrerillo.

guacharro m. 'cría de pájaro'.

Alcalá, Voc. and. s.v. 2 guacho m. Polluelo de gorrión; cf. s.v. 2 guacharra, guacharrazo, guacharrear, guacharreo y guacharrón, -na; ALEA, lám. 386, m. 403 Cría del pájaro: Ma 201 guacharriyo; y en muchos puntos de Jaén, Granada y noreste de Córdoba, guacharro. 
MAPA 6

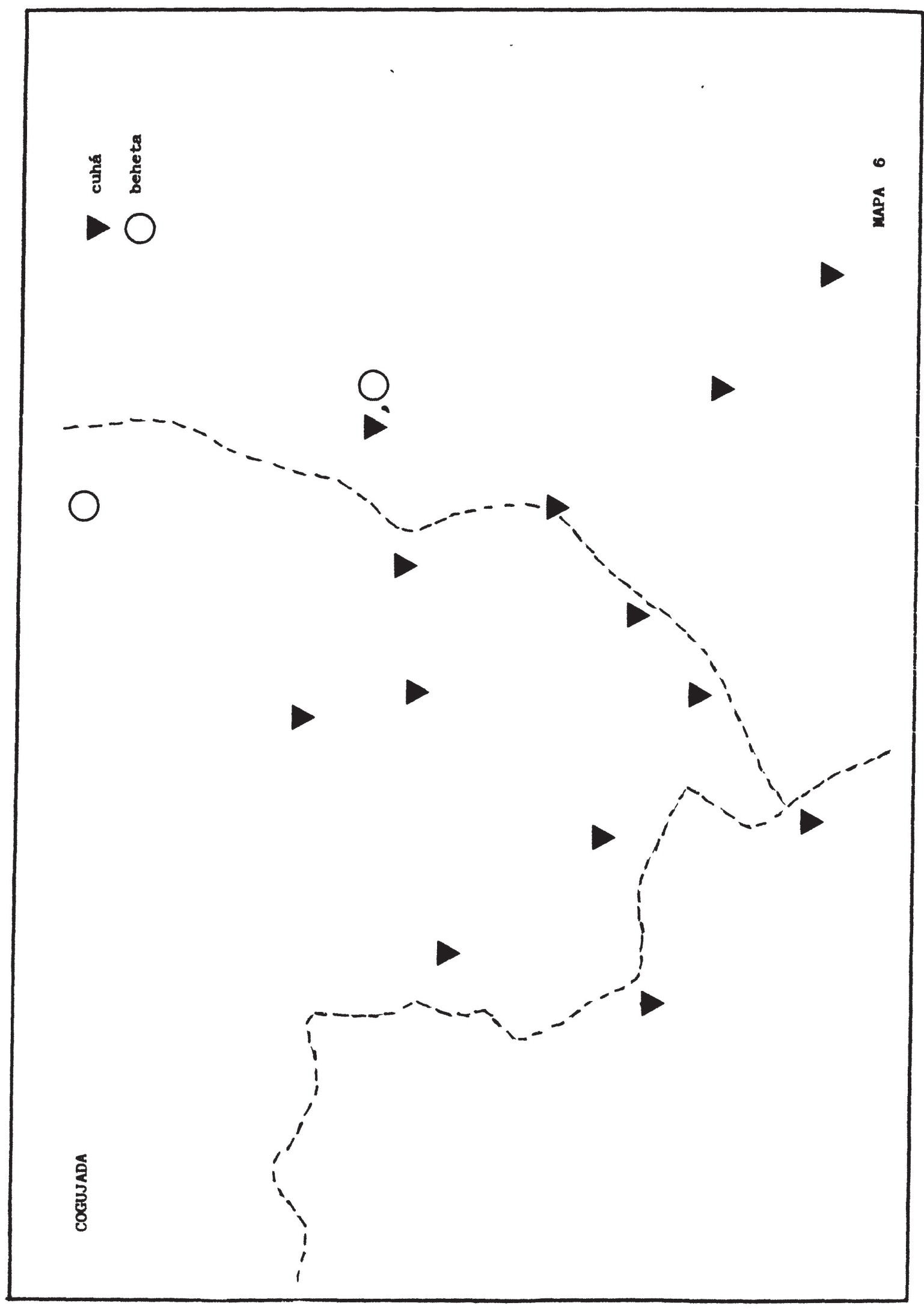


fifita f. 'aguzanieves, pajarita de las nieves'.

Es la designación más extendida en el área del treviño (ver infra s.v. tifa). En los Ventorros de Balerma, también hemos encontrado filfirita. Ver Cabra-Vocab., s.v. fifita «Aguzanieves (Doña Mencía)» y Fernández, Priego, s.v.; ALEA lám. 397, m. 414 Aguzanieves: Co 609 Iznájar y Gr 303 Algarinejo, fifita; Gr 306 Brácana, filfita; vid. Mondéjar, Aguzanieves, 283 ss. y Llorente, Comentario, 311.

bagüíya f. 'Abubilla. Upupa eppos'.

ALEA lám. 398, m. 415 Abubilla: Co 609 Iznájar, hagüíya, como en muchas localidades encuestadas del Sur de Córdoba, Oeste de Granada y Norte de Málaga; Alvar, Tabobo, 481-483: las formas andaluzas con aspirada, como hagüíya, dominantes en el centro y oriente de la región hay que ponerlas en relación con el árabe hûdbud 'abubilla', que por cruce con las formas románicas ha dado muchas variantes.

pichin, pinchin m. 'Petirrojo. Erithacus rubecula'.

Toro, Voces s.v. pichilin. «adj. ¿Muy pequeño?. "Tamaño como un ochavo pichilín" V. Picholín y Chipilín. Cf. el gitano pici, pequeño, y el vizcaíno pichi, pequeño [...]»; Alcalá, Voc. and., s.v. pichín 'm. Pechirrubio', pájaro (Prov. de Granada)'; s.v. pichin colorao 'm. Pechirrubio, pichi colorado. (Loja, Granada)'; s.v. pichito, 'm. Pechirrubio, pájaro'; s.v. pinchín 'm. Pájaro pequeño de capa parda y pechuga ocre'; s.v. 1 pinchito m. Petirrojo, pájaro; ALEA lám. 388, m. 405 Petirrojo: Co 609 pichin. En muchos puntos de Granada, Jaén y Málaga, pinchín.

tifa f. 'aguzanieves, pajarita de las nieves'.

Designación de El Higueral, Fuentes de Cesna y La Celada. Vid. supra, fifita; Alcalá, Voc. and. s.v. tifa f. Pajarita de las nieves. (Fernán Núñez, Córdoba); Cabra-Vocab., s.v. tifa «Cierto pájaro del tamaño del gorrión de cola larga, que anda por el surco detrás de las yuntas. Debe ser el aguzanieves'». En Puente Genil (Córdoba), según nuestros propios datos, se dice tifita. 
MAPA 7

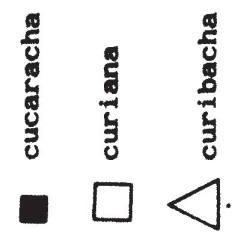

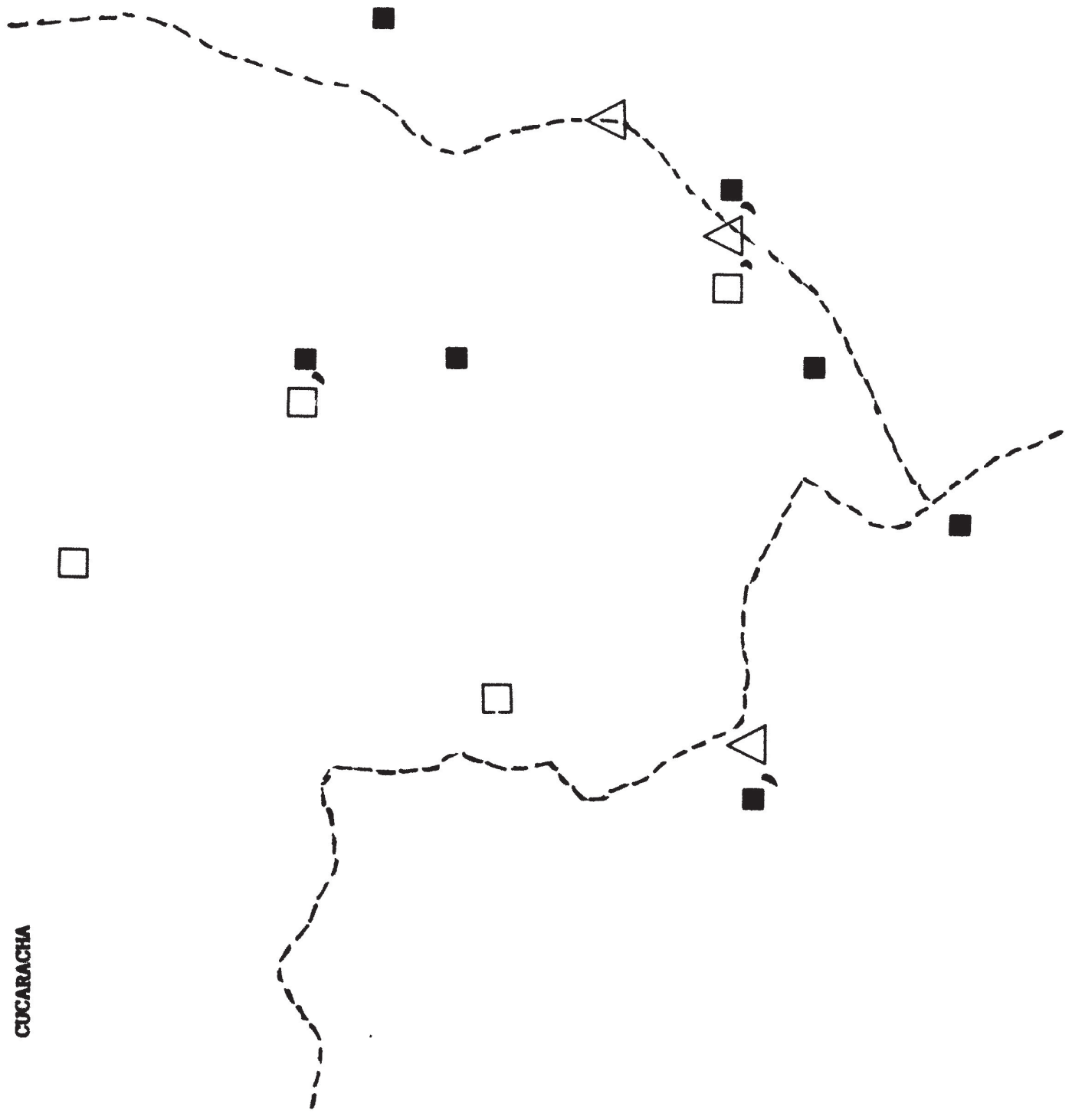




\subsubsection{Insectos}

palomita f. 'cualquier mariposa'.

Toro, Voces s.v. paloma. s.f. Paloma negra. Mariposa [...] En Murcia y Méjico, mariposa. Ver ALEA lám. 381, m. 396 mariposa, en Co 609 Iznájar: la mariposa es grande y la palomita pequeña; el área de palomita es básicamente Málaga, Sur de Córdoba y Sevilla; ver Uritani, Diminutivos, 215 216; García Mouton, Nombres, 195. El sufijo está lexicalizado.

tábarro $\mathrm{m}$. 'avispa, insecto venenoso'.

Toro, Voces trae tabarro, como voz oída por él: «s. m. Tábano. [...]». Cabra-Vocab., s.v. tabarro [tábā̄o] «Avispa (Doña Mencía) // tabarro terriso 'especie de avispa que hace un pequeño panal en tierra'». García de Diego, Etimologías, «de tábano se ha formado tábarro en Andalucía con la acepción de 'tábano, insecto'», 359-363. Alcalá, Voc. and., s.v. tábarro m. Tábano, tabarro; ver ALEA lám. 366, m. 379 Tábano (Tabanus Dovinus) y lám. 578, m. 625 Avispa: tábarro; Alvar, Estructura: tabarro se da en el centro mismo de Andalucía.

curiana f. 'cucaracha'.

La difusión geográfica de cucaracha, curiana y curibacha en el treviño puede verse en el mapa n. ${ }^{\circ}$ 7; Cf. ALEA lám. 371, m. 385 Co 609 Iznájar: cucaracha y en Ma 201 Villanueva de Algaidas, curibacha; Mondéjar, Andaluz, \$ 6.4. trae curiana 'cucaracha' como andalucismo en Valera. Ver también Ariza, Notas, p. 1074 y n. 72, curiana, claro andalucismo en la prosa de Juan Valera. La forma curiana sólo se documenta en las localidades cordobesas del treviño. Probablemente, de un cruce entre curiana y cucaracha ha surgido curibacha, en puntos de las provincias de Granada y de Málaga.

\section{EL HOGAR}

peana f. 'la plataforma elevada varios centímetros sobre el suelo, donde se hace el fuego'.

Alcalá, Voc. and. s.v. 1 peana 'f. Hogar de la cocina, fogaril (Prov. de Córdoba) «Se arrodilló en la peana, juntó los leños desperdigados y se puso a soplar inflando sus carrillos...»' (cita de Miguel de Castro, novelista iznajeño); Cf. Salvador, Cúllar-Baza, s.v. peana 'lo que queda del tronco después de talar el árbol, tocón'. 
rincón $\mathrm{m}$. 'el hogar, la chimenea'.

Alcalá, Voc. and. s.v. 1 rincón «m. Por antonomasia se dice familiarmente de cada uno de los flancos del hogar»; Molina, Léxico, 17: rincón 'hogar' es un nombre metonímico «procedente de una circunstancia concomitante»; Cf. Pizarro, Pedroches, 95, s.v. rincón.

\section{LA GASTRONOMIA}

\subsection{Comidas}

papueca f. 'masa de harina con bacalao, perejil y ajo que se fríe y se toma con miel'. Es comida característica de la Semana Santa.

El escritor y periodista iznajeño Cristóbal de Castro empleó en su novela Los hombres de bierro este término: «... soplao, jinchao, con camoflete lo mesmito que una papueca» (apud Alcalá, Voc. and., s.v. papueca. «f. Fritura hecha con masa de harina de garbanzos»). Cf. Fernández, Priego, s.v. papueca. Sust. f. Masa-clara frita que se suele emborrizar en azúcar.

pimentón m. 'gazpacho de tomate, pimiento, pepino, ajo, aceite, vinagre y pan rallado'

Toro, Voces s.v. pimentón (voz oída por él). s.m. Gazpacho de pimiento, pepino y tomate; Salvador, Cúllar-Baza, s.v. pimentón 'cierto guiso a base de patatas, morcilla o pescado, y caldo con pimentón'. (El 'pimentón' se llama en Cúllar pimiento molío, como en murc.).

porra, porriya f. 'salsa de almendras y miga de pan, que se puede preparar con patatas, espárragos, bacalao, morcilla, etc.

Se trata de la porra de Málaga, como puede verse en el ALEA, lám. 745 Resumen estadístico de la alimentación andaluza; Cf. Alcalá, Voc. and., s.v. 1 porra f. 'Majado hecho con aceite y miga de pan, parecido a la mayonesa'; Toro, Voces s.v. porrón (voz oída por él) s. m. Cierta salsa de ajos.

Otra modalidad, la porra fría, es el conocido 'salmorejo', 'la masa del gazpacho andaluz, con habas verdes, trozos de naranja, huevo cocido, etc.' Ver Alcalá, Voc. and., s.v. 2 porra 'Salmorejo. (Prov. de Sevilla)'.

sobrebusa f. 'guiso de habas en granazón con morcilla, chorizo, sofrito de cebolla, tomate y pimiento, condimentado con ajo, perejil y culantro'. 
Alcalá, Voc. and. s.v. 1 sobrebusa f. Guiso de pescado en salsa; 2 sobrebusa f. Potaje de habas secas; Fernández, Priego, s.v. sobrejusa (Sust. f.) Guiso que se hace cociendo habas secas o al menos granadas. Toro, Voces s.v. sobrebusa: «En Acad., pro. And.: Guisado de pescado, etc. Hay otra acepción en Lope de Rueda... "Los vi [buñuelos] con aquella sobrehusa encima". Cotarelo observa (Glosario) que Covarrubias trae dos significaciones, una de capirotada vulgar, y otra de "cierta salsa que se echa en algunos guisados" y agrega: como se ve, también podía ser dulce».

Ver Mondéjar, Andaluz, $\$$ 6. 4. sobrehusa 'guiso de pescado sobrante el día anterior' es andalucismo en Juan Valera; Ariza, Notas, p. 1074 y n. 79: sobrebusa, andalucismo inconsciente de Valera.

sapatúa, zapatúa adj. 'se aplica a la aceituna de mesa que tiene mal sabor por haberse estropeado o no estar bien aliñada'.

Cf. Alcalá, Voc. and., s.v. zapatera adj. Aceituna añejada y con mal gusto; Salvador, Cúllar-Baza, s.v. zapatúo 'mal cocido' («Estas papas están zapatúas y no se pueden comer»); García de Cabañas, Alpujarra, 33: zapatúo, -a 'alimento mal cocido, zapatero'; Criado, Estudio, s.v. zapatera.

machacandero m. 'mano del mortero'.

Toro, Voces s.v. machacandero (prov. de Granada): Machacadera; Alcalá, Voc. and., s.v. remite a machacandera 'maja o majadera'. Machacandero 'mano del almirez' y 'mano del mortero' es palabra andaluza, según Molina, Léxico, 14.

reyeno $\mathrm{m}$. 'fiambre característico del carnaval, hecho con huevos, pan rallado, carne, jamón, perejil, ajo, azafrán y pimienta, embutido en tripas de cerdo y hervido'.

Ver Salvador, Cúllar-Baza, s.v. relleno [reyéno] 'embutido de carne de cerdo u otro animal, jamón, huevos, etc.'.

\subsection{Repostería}

carete $m$. 'merengue con el que se da a los roscos un baño blanquísimo, deslumbrante'. Se ha creado un verbo tr. encaretar, muy usual. Típicos y sabrosos son los roscos de vino o de buevo, encaretaos. ¿De (na)carete, por la semejanza de su blancura con la del nácar? La aféresis y el sufijo -ete no planterían dificultades. 
Cf. Toro, Voces, s.v. lustre. "s. m. Baño de clara de huevo batida con azúcar que se da a ciertos pasteles, el bienmesabe de la Acad. Cf. Enlustrado, bizcocho cubierto de azúcar, en Costa Rica (Gagini)"; Alcalá, Voc. and. s.v. carete «m. Baño que se da a los roscos con clara de huevo batida con azúcar en punto de merengue (Prov. de Córdoba) "Dale carete a esos roscos y ponlos al sol"».

emborrisar 'azucarar algunos dulces', 'rebozar con huevo, pan, etc.'.

Ver Toro, Voces, s.v. emborrizar "v. a. Envolver las viandas en huevo batido, para freirlas: sesos emborrizados"; García de Cabañas, Vocabulario, 48 , emborrizar «tr. Rebozar, bañar en harina o en pan seco y molido la carne y el pescado [...]»; Criado, Estudio, s.v. emborrizar.

\section{JUEGOS}

peluca f. 'cierto juego propio de niñas', con cinco chinas que se arrojan al aire y hay que recoger luego, de acuerdo siempre con unas complicadas reglas que exigen gran habilidad, al tiempo que se van recitando unos versillos. El ganador le da peluquita al perdedor (un pellizco) al terminar esta relación «Peluquita uno, peluquita dos, peluquita tres, el sacatacos y el pellizquito inglés». De estructura muy compleja, el juego consta de al menos 10 ó 15 fases, con nombres como: los pompos, la casita, el puente, la tijereta, el buevo, etc.

Cf. ${ }^{20} \mathrm{DRAE}$, s.v. peluca «3. fig. y fam. Reprensión acre y severa dada a un inferior»; Pagés, Diccionario, s.v. peluca, añade: «Dar una peluca es lo mismo que dar una reprensión ó reprimenda fuerte; imponer un castigo severo por un superior á un inferior. Esta locución es de origen monástico. V. J. Bastús».

No hemos documentado el nombre del juego en ningún vocabulario, ni tampoco referencias del mismo. También se denomina (juego de) las chinas y en Pozoblanco, juego de los pinches (Alcalá, Voc. and. s.v. pinche 'pincho, aguijón'). Es posible que el origen del nombre esté en la expresión dar peluca 'pellizcar', a nuestro parecer.

\section{ARTESANIA DEL ESPARTO}

clinea, crinea f. 'cuerda de esparto de cinco ramales'. Se ha especializado el término para un tipo muy concreto de cuerda. 
Ver ${ }^{20}$ DRAE crizneja «2. Soga o pleita de esparto u otra materia semejante». Alcalá, Voc. and., s.v. crineja f. Soga de cinco liñuelos; DCECH II, s.v. crizneja «Hoy, como en el Siglo de Oro, el vocablo se emplea en Andalucía (crineja 'soga de cinco liñuelos' [...]) y en varios puntos de América: clineja 'trenza' [...], clineja 'la trenza o crencha del cabello en las mujeres, tejida en tres ramales o madejas gruesas' [...], y crisneja».

hibcá(l), ibcá, ibcaliyo, ebcaliyo $\mathrm{m}$. 'hiscal, cuerda de esparto de tres ramales'. Variantes fonéticas: ibcá, hibcaliyo, ihcaliyo, ebcá. El área cordobesa de hiscal en el treviño puede verse en Galeote, Habla, 210, mapa 27 y comentario del mismo en p. 157.

Cf. ${ }^{20} \mathrm{DRAE}$, s.v. hiscal; Toro, s.v. jical. «s. m. ¿Soga? "Sujetas a unos postes con jical de esparto"»; Alcalá, Voc. and. s.v. hescal «m. Hiscal, ramal (Prov. de Córdoba) "Trae un hescal y ataré este lío"»; s.v. hicar «m. Trozo de cuerda de esparto o palma. Hiscal, bescal» (con una cita literaria de Fernán Caballero); s.v. jicar «Hicar. "A Nuestro Señor Jesucristo lo ataron con un jicar"»; Cabra-Vocab., s.v. iscal [ihkal] «Hiscal. Atadura de esparto con la que se ata la mies». Es conocido en Adamuz y en Fernán Núñez, ver De Jong, Adamuz, 159.

DCECH, s.v. hiscal, «'cuerda de esparto de tres ramales', palabra rara de origen incierto. $10^{2}$ doc.: hyscal, princ. S. XV. [...] semánticamente se podría pasar en rigor de 'bozal' (sentido que tiene el diminutivo fiscella en latín) a 'cuerda colgante, cinturón flojo'. Pero esto es muy dudoso y peor es el aspecto fonético, pues la $b$-indicaría palabra del fondo particular del idioma, y entonces la I breve de FISCUS [...] no estaría de acuerdo con la $i$ castellana. Antes de hacer más averiguaciones habrá que asegurar mejor la existencia y el significado exacto de este vocablo, que no ha sido estudiado por los etimologistas ni existe en otros romances». ¿Es curioso que con hiscal aún se hagan bozales en el treviño!

En el ALEA se documenta hiscal al menos en dos mapas diferentes: m. 46 vencejo para atar el haz (en cuatro de los seis puntos donde la respuesta es izcal, se añade 'de esparto') y m. 545 (lingüístico-etnográfico) cierre de la encella 'tomiza con que se cierra el molde del queso: [i'ká],

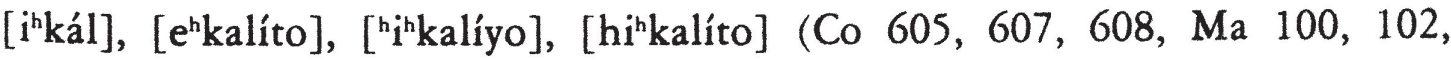
Se 602, Ca 202). Esto nos lleva a pensar que hiscal designaba en el ALEA el 'vencejo de esparto' (que ocasionalmente o de forma habitual se emplea en algunas localidades para amarrar los haces) y no el 'vencejo de mies', así como la "tomiza de la encella".

Cf. la transcripción con $-z$ implosiva en Andalucía de Fernández-Sevilla, Léxico, 156: «Izcal (en Córdoba, Jaén y Granada) es palabra extraña, de la 
que no he podido encontrar referencias precisas» y en la n. 46 la remonta al lat. ESCA 'yesca'; para Alvar, Atlas, $\ 20, \$ 60.2 .3 .:$ es un derivado de ESCA; $\$ 61.4, \$ 67.2$ : falta en Alcalá Venceslada.

\section{TIEMPO ATMOSFÉRICO}

chabca f. 'bochorno, calor sofocante del mediodía o de las horas de calma'.

Hemos documentado también bocbobno y flama con este mismo sentido, ver ALEA lám. 1396, m. 1517 flama: en Co 609, flama, como en gran parte de Andalucía. Cf. ${ }^{20} \mathrm{DRAE}$ s.v. chasca «/2. Ramaje que se coloca sobre la leña dispuesta para hacer carbón».

\section{MANUEL GALEOTE}

Dpt. de Filología Española.

Universidad de Granada.

\section{CLAVE BIBLIOGRÁFICA}

Alcalá, Voc. and.: Antonio Alcalá Venceslada, Vocabulario andaluz (Madrid: Gredos, 1980) (reimpresión).

ALEA: Atlas Lingüístico y Etnográfico de Andalucía. Dirigido por Manuel Alvar, con la colaboración de Antonio LlORENTE MALDONADO DE GuEVARA y Gregorio SALVADOR, I-VI. El tomo VI está redactado por A. Llorente y M. AlVAR con la colaboración de J. Mondéjar (Universidad de Granada, CSIC, 1960-1973).

Alonso, Trueques: Amado Alonso, «Trueques de sibilantes en antiguo español», NRFH, I, 1 (1947), 1-12.

Alvar, Atlas: Manuel Alvar, «Atlas lingüísticos y diccionarios», LEA, IV/2 (1982), 253323.

- Estructura: Manuel ALVAR, «Estructura del léxico andaluz», BFUCh, XVI (1964), 5 12.

- Tabobo: "Tabobo (Un falso guanchismo en las designaciones de la 'abubilla')», Anuario de Estudios Atlánticos, 27 (1981), 477-483.

ArizA, Notas: Manuel ARIZA, «Notas sobre la lengua de Juan Valera», Actas del I Congreso Internacional de Historia de la Lengua Española (cit. Actas I CHLE) (Madrid: Arco Libros, 1988), II, 1065-1075.

BORREGO, Sociolingüística: Julio BORREGo NIETO, Sociolingüistica rural. Investigación en Villadepera de Sayago (Universidad de Salamanca, 1981).

Cabra-Vocab.: Lorenzo Rodríguez-CAstellano, «El habla de Cabra. Vocabulario», $A O$, $\mathrm{V}$ (1955), 351-381.

Cano, Osuna: Rafael Cano Aguilar y Manuel Cubero Urbano, «El léxico del olivo en Osuna», Archivo Hispalense, LXII, 189 (1979), 41-69. 
CARrasco, Baeza: Pilar Carrasco Cantos, Contribución al estudio del habla rural de Baeza (Jaén) (Jaén: Instituto de Estudios Giennenses, CSIC, Excma. Diputación Provincial, 1981).

Criado, Estudio: Matilde y Joaquín Criado Costa, "Estudio del léxico de San Sebastián de los Ballesteros (Córdoba)», Boletín de la Real Academia de Córdoba de Ciencias, Bellas Letras y Nobles Artes (cit. BRAC), LV, 106 (1984), 47-68.

Chamorro, Derivados: José María Chamorro MARTfNez, "Glayo, galayo y layo ¿derivados metafóricos del latín GLADIUS?», José MONDÉJAR (ed.), Stvdia litteraria atque lingvistica N. Marín, J. Fernández-Sevilla et P. González oblata (Universitas Granatensis, 1988), 23-32.

DCECH: Joan Corominas y José Antonio PASCuAL, Diccionario Crítico Etimológico Cas. tellano e Hispánico (Madrid: Gredos, 1980-83).

DE JONG, Adamuz: Jelly DE JONG, «De Adamuz y Fernán-Núñez (Cuestiones dialectológicas)», BRAC, LVIII, 112 (1987), 149-165.

Dicc. And.: Diccionario Andaluz biográfico y terminológico (Sevilla: Ediciones Andaluzas, S.A., I (A), 1980; II (B-E) y III (F-K), 1981).

${ }^{20}$ DRAE- Real ACADEmia Española, Diccionario de la lengua española (Madrid, ${ }^{201984),}$ 2 vols.

Fernández, Priego: Francisco Fernández Pareja, Vocabulario de Priego de Córdoba y su comarca (Córdoba: Monografías de «Espiral», 1982).

Fernández-Sevilla, Léxico: Julio Fernández-Sevilla, Formas y estructuras del léxico agricola andaluz. Interpretación y estudio de 200 mapas lingüísticos (Madrid: CSIC, 1975).

FONT QUER: Dioscórides: P. FONT QUER, Plantas medicinales. El Dioscórides renovado (Barcelona: Labor, ${ }^{8} 1983$ ).

GAleote, Habla: Manuel GAleote, El habla rural del treviño de Iznájar, Villanueva de Tapia y Venta de Santa Bárbara (Granada: Ilmo. Ayuntamiento de Iznájar (Córdoba), Ediciones TAT, 1988).

Garcia de CABAÑas, Alpujarra: María Jesús Garcfa de Cabañas, Vocabulario de la Alta Alpujarra, Anejo XIV del BRAE (Madrid: Real Academia Española, 1967).

García DE DiEgo, Etimologías: Vicente GARcfa DE Diego, Etimologías españolas (Madrid: Aguilar, 1964).

García Mouton, Nombres: Pilar Garcia Mouton, «Motivación en nombres de animales», LEA, IX/2 (1987), 189-197.

Garulo, Arabismos: Teresa Garulo Muñoz, Los arabismos en el léxico andaluz (Madrid: Excma. Diputación Provincial de Córdoba, Instituto Hispanoárabe de Cultura, 1983).

Guell, Malas hierbas: Francisco Guell, Malas hierbas. Diccionario clasificatorio ilustrado (Barcelona: Oikos-Tau, 1970).

Guillén, Habla culta: Rosario Guillén Sutil, El babla culta de Sevilla. Estudio léxico Sevilla: Alfar, 1987).

Llorente, Coincidencias: Antonio Llorente Maldonado de Guevara, «Coincidencias léxicas entre Andalucía y el Valle del Ebro», Homenaje al Prof. Tomás Buesa Oliver, $A F A$, XXXVI-XXXVII (1985), 347-375.

Llorente, Comentario: Antonio Llorente Maldonado de Guevara, «Comentario de algunos aspectos del léxico del tomo I del ALEICan», Actas del II Simposio Internacional de Lengua Española (Gran Canaria: Ediciones del Excmo. Cabildo Insular, 1984), 283-330; ahora en Antonio LlORENTE, El léxico del tomo I del "Atlas lin- 
güístico y etnográfico de las Islas Canarias" (Cáceres: Servicio de Publicaciones de la Universidad de Extremadura, 1987).

Martinez-Moya, Léxico: Juan Martinez Marf́n y Juan Antonio Moya Corral, el léxico del olivo y la almazara en la provincia de Jaén (Granada: Universidad de Granada, Instituto de Estudios Giennenses, 1982).

MCMENAMin, Geografía: Jerry MCMEnAmin, «Geografía dialectal y sociolingüística: un ejemplo andaluz», NRFH, XXVII, 2 (1978), 276-296.

Millán, Aragonesismos: Fernando Millín ChIVITE, «Aragonesismos léxicos en el ALEA: mapas 7-92», Homenaje al Prof. Tomás Buesa Oliver, AFA, XXXVI-XXXVII (1985), 405-416.

Molina, Léxico: José Andrés de Molina, Introducción al estudio del léxico andaluz (Resumen de Tesis Doctoral) (Secretariado de Publicaciones, Universidad de Granada, 1971).

Moliner, Diccionario: María Moliner, Diccionario de uso del español (Madrid: Gredos, 1983) (reimpresión).

MONDÉjAR, Aguzanieves: José MONDÉjar, «Algunos nombres románicos de la 'aguzanieves' («Motacilla alba» L.) (ALEA, II, 414; ALEANR, IV, 458; ALEICan, 310)», Homenaje al Prof. Tomás Buesa Oliver, AFA, XXXVI-XXXVII (1985), 275-311.

- Andaluz: José MONDÉJAR, «Andaluz», in: Lexikon der Romanistischen Linguistik (LRL), VI (Tübingen: Max Niemeyer Verlag) (en prensa).

- Bibliografía: José MONDÉJAR, Bibliografía sistemática y cronológica de las bablas andaluzas (Granada: Los Libros del Caballero del Verde Gabán, Editorial Don Quijote, 1989).

- Hablas andaluzas: José MONDÉJAR, «Las hablas andaluzas», Andalucía (Sevilla: Editoriales Andaluzas Unidas, 1986), 289-307.

- Orígenes: José MONDÉJAR, «En los orígenes de la dialectología andaluza: II. Etapa precientífica», Estudios Románicos dedicados al Prof. Andrés Soria Ortega (Granada: Universidad de Granada, 1985), I, 193-220.

- Verbo: José MONDÉJAR, El verbo andaluz. Formas y estructuras, Anejo XC de la RFE (Madrid: CSIC, 1970).

MUÑoz, Murciano: José MUÑoz GARRIGÓs, «Dialectología y lexicografía: Notas sobre el dialecto murciano», LEA, X/1 (1988), 73-80.

Navarro, Voces: Ana Isabel Navarro Carrasco, «Voces de creación metafórica en el ALEA», LEA, X/1 (1988), 107-114.

Narbona, Hablas: Antonio NArbona - Ramón Morillo-Velarde, Las hablas andaluzas (Publicaciones del Monte de Piedad y Caja de Ahorros de Córdoba, 1987).

Ortega, El Sur: Francisco ORTEGA AlBA, El Sur de Córdoba. Estudio de geografía agraria (Publicaciones del Monte de Piedad, Córdoba, 1974), 2 vols.

PAGÉs, Diccionario: Aniceto de PAGÉs, Gran Diccionario de la lengua castellana, IV (Barcelona, [s.a.]).

Pizarro, Pedroches: Juan Pizarro, Vocabulario de los Pedroches (Córdoba: Excma. Diputación Provincial, 1988).

Rafel, Areas léxicas: Joaquín Rafel Fontanals, «Áreas léxicas en una encrucijada lingüística», RFE, LVII, 1-4 (1974-75), 231-275.

Salvador, Cúlllar-Baza: Gregorio Salvador, El habla de Cúllar-Baza. Vocabulario, PALA, II, 3 (Granada, 1958).

- Lexicografía: Gregorio SALVADOR, «Lexicografía y geografía lingüística», RSEL, 10, 1 (1980), 49-57. 
Soriano, Vocabulario: Justo Garcia Soriano, Vocabulario del dialecto murciano. Con un estudio preliminar y un apéndice de documentos regionales (Editora Regional de Murcia, 1980) (edición facsímil de la primera edición, Madrid, 1932).

TORO, Voces: Miguel de TORO Y GISBERT, «Voces andaluzas (o usadas por autores andaluces) que faltan en el Diccionario de la Academia Española», RHi, XLX, 116 (1920), 313-647.

Uritani, Diminutivos: Nozomu Uritani y Aurora BerRueta de URITANI, «Los diminutivos en los atlas lingüísticos españoles», LEA, VII/2 (1985), 203-235.

VAquero, Léxico: María Teresa Vaquero de RAMfrez, «El léxico agrícola en el español de Puerto Rico», LEA, X/2 (1988), 255-268.

Villena, Vocalismo: Juan Andrés Villena Ponsoda, Forma, sustancia y redundancia contextual: el caso del vocalismo del español andaluz (Málaga: Universidad de Málaga, 1987).

El estudio lingüístico de las formas léxicas (relativas a cultivos, labores de recolección, plantas silvestres, animales, etc.), recogidas en las localidades donde convergen los límites provinciales de Córdoba, Granada y Málaga, nos muestra, por una parte, el polimorfismo debido al cruce de isoglosas en dicha área y, por otra, la inestabilidad sociolingüística del habla rural, caracterizada por el arcaísmo.

The linguistic study of the lexical forms (concerning to cultivation, gathering works, wild plants, animals, etc.), compiled in the localities where provincial limits of Córdoba, Granada and Málaga converge, shows, on one hand, the polymorphism due to the cross of issogloss in the mentioned area and, on the other hand, the sociolinguistic instability of the rural speech, distinguished by the archaism. 